\title{
Physiological and pathophysiological roles of excitatory amino acids during central nervous system development
}

\author{
John W. McDonald ${ }^{1,3}$ and Michael V. Johnston ${ }^{1,2}$ \\ Departments of ${ }^{1}$ Neurology and ${ }^{2}$ Pediatrics, the Johns Hopkins University School of Medicine and the Kennedy Research Institute, Baltimore, \\ MD 21205 (U.S.A.) and ${ }^{3}$ University of Michigan, Ann Arbor, MI 48109 (U.S.A.)
}

(Accepted 16 January 1990)

Key words: Excitatory amino acid; Development; Glutamate; N-Methyl-D-aspartate; Plasticity; Central nervous system; Neurotoxicity

\section{CONTENTS}

1. Introduction

2. Pharmacology of EAA receptors

2.1. NMDA receptors

2.2. Non-NMDA receptors

3. Ontogeny of EAA pathways

3.1. Visual associated structures

3.2. Non-visual cortical areas

3.3. Hippocampal formation

3.4. Non-NMDA receptors in selected areas

3.5. EAA-stimulated phosphatidyl inositol hydrolysis

3.6. Physiological changes

4. Promotion of neuronal survival, growth and differentiation

5. Regulation of neuronal circuitry and cytoarchitecture

6. Regulation of activity-dependent synaptic plasticity

6.1. LTP-forms of learning and memory

6.2. Experience-dependent synaptic plasticity: visual pathways

7. Mechanisms of EAA neurotoxicity

8. Developmental alterations in EAA-neurotoxicity

9. Role of EAAs in developmental neurologic disorders

9.1. Hypoxia-ischemia

9.2. Sustained seizures

9.3. Disorders of amino acid metabolism

9.3.1. Non-kctotic hyperglycinemia

9.3.2. Sulfite oxidase deficiency

9.4. Endocrinopathies

10. Therapeutic potential of EAA-receptor antagonists

10.1. Acute therapy

10.2. Chronic therapy

11. Conclusions

12. Summary

Acknowledgements

Abbreviations

References

Correspondence: J.W. McDonald, Neuroscience Building, Rm. 1015, 1103 E. Huron, Ann Arbor, MI 48109, U.S.A. 


\section{INTRODUCTION}

A number of recent reviews have focused on the pharmacology, physiology and pathophysiology of EAAs in the mature central nervous system $(\mathrm{CNS})^{32,58,79 \text {, }}$ $122,140,146,192,195$. The majority of these aspects are also common to the developing CNS. However, EAAs also play additional physiological and pathophysiological roles during CNS development. A rapidly growing body of evidence suggests that EAAs are involved in a variety of physiological processes during development, including regulation of: neuronal survival, dendritic and axonal structure, synaptogenesis and activity-dependent synaptic plasticity. EAAs play a critical role in shaping neuronal circuitry and in learning and memory. Markers of EAA pathways undergo major changes during the postnatal period. Excessive activation of EAA receptors, however, can produce neuronal injury and death. The developing brain has a unique ontogenic profile of susceptibility to toxicity produced by agonists selective for each of the EAA receptor subtypes. Normal CNS development appears to require an optimum level of EAA receptor activity; underactivity may delay or disrupt development and overactivity can produce brain damage. Thus, aberrations in the regulation of the activity of EAA pathways could potentially disrupt critical developmental processes and may underlie several developmental neurologic disorders.

The goal of this review is to integrate a diverse literature on the physiological and pathophysiological roles of EAA during development of the CNS. First the role of EAA in neurotransmission, the characteristics of EAA receptor subtypes and their expression during development will be summarized. The next 3 sections discuss the neurotrophic influences of EAAs, their participation in the development of neuronal circuitry and cytoarchitecture and in the regulation of activitydependent synaptic plasticity during development. Subsequent sections review the pathophysiological roles of EAAs during development and the characteristics and developmental patterns of EAA neurotoxicity. Finally, the possible roles of EAAs in developmental neurologic disorders and the therapeutic potential of EAA receptor antagonists in relation to these disorders will be discussed.

\section{PHARMACOLOGY OF EAA RECEPTORS}

EAA neurotransmission in the CNS of mammals is mediated principally by glutamate and structurally related compounds ${ }^{58,64,238}$. Glutamate is the most abundant amino acid in the $\mathrm{CNS}^{64}$. The majority of glutamate in the brain, however, is involved in intermediary metabo- lism in both neurons and glia and only a fraction of the total glutamate pool participates in neuronal signaling. Glutamate, stored in synaptic vesicles, is released from presynaptic terminals by membrane depolarization in a $\mathrm{Ca}^{2+}$-dependent fashion ${ }^{152,182,197}$. The concentration of glutamate in the synaptic cleft can reach millimolar levels and the ability of glutamate to produce post-synaptic excitation is limited by both neuronal presynaptic and glial high-affinity uptake systems (see Fig. 1) ${ }^{64}$.

EAA pathways are abundant in the brain and include cortical association, corticofugal and subcortical pathways ${ }^{42,61}$. It is estimated that EAAs are the primary neurotransmitter in approximately $50 \%$ of the synapses in the mammalian forebrain. In fact, nearly all neurons can be excited by glutamate ${ }^{51}$. The excitatory responses to glutamate are mediated by several receptor subtypes that are commonly classified as $N$-methyl-D-aspartatc (NMDA) and non-NMDA type glutamate receptors

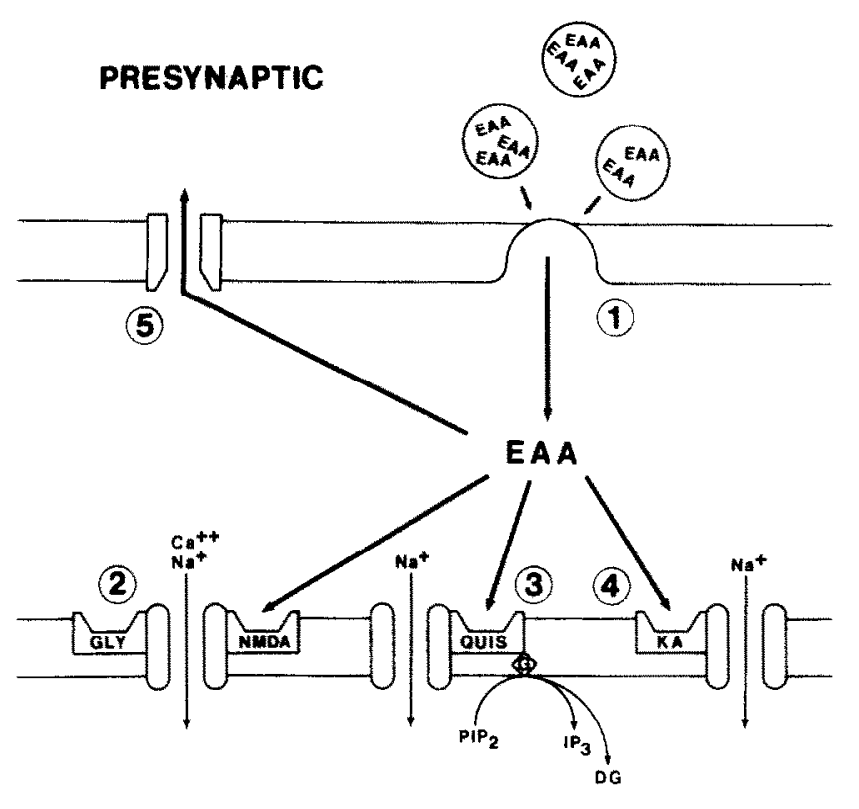

POSTSYNAPTIC

Fig. 1. This is a diagram of the EAA synaptic components that contribute to synaptic transmission, second messenger generation and cessation of these responses. (1) Glutamate and related EAAs are released from presynaptic neuronal tcrminals in a calciumdependent process by depolarization of the presynaptic neuron. (2)-(4) Once released into the synaptic cleft, glutamate can depolarize the post-synaptic neuronal membrane by binding to at least 3 subsets of EAA receptors. Activation of (2) the NMDA receptor channel complex, (3) quisqualate receptors or (4) kainate receptors can produce cationic fluxes through receptor associated ionophores. Alternatively, a subset of quisqualate receptors are linked with phospholipase $C$, which activates phosphoinositol hydrolysis and generates the second messengers inositol triphosphate $\left(I_{3}\right)$ and diacylglycerol (DG). The distribution of these subtypes of EAA receptors in brain can be examined with radiolabeled ligands specific to each receptor subtype. (5) The excitatory actions of glutamate on post-synaptic membranes is inactivated by a presynaptic, high-affinity, energy-dependent transport process. 
based on their preferential responses to synthetic EAA receptor agonists ${ }^{239}$. The major agonists used to differentiate non-NMDA receptors are quisqualate and kainate. The non-NMDA receptors appear to mediate fast excitatory synaptic responses. A group of quisqualate preferring receptors (described as 'metabotropic') is coupled to phospholipase $C$ and receptor activation leads to phosphatidyl inositol hydrolysis and production of second messengers ${ }^{156,157,214}$. NMDA receptors also participate in synaptic transmission but activation may include more long-lasting post-synaptic events ${ }^{43,89,161,228}$. A detailed review of the pharmacology and physiology of EAA receptors is beyond the scope of the present review. However, more detailed information can be obtained in several excellent reviews on this subject ${ }^{122}$. $146,207,224$.

\subsection{NMDA receptors}

Whereas glutamate interacts with all the EAA receptor

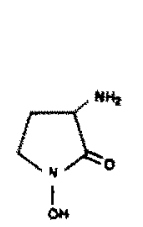

HA-966

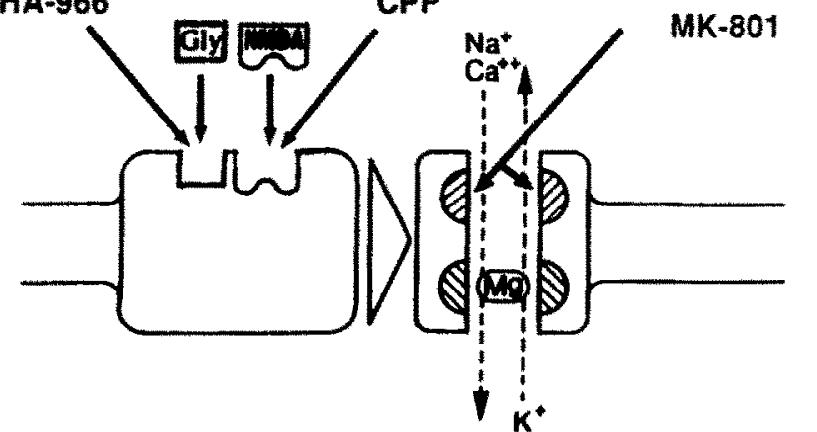

Fig. 2. This diagram outlines current information about the components of the NMDA receptor/channel complex based on biochemical and electrophysiological evidence. The NMDA recog* nition site is coupled to a cationic channel that is permeable to both $\mathrm{Ca}^{2+}$ and $\mathrm{Na}^{+}$. A glycine modulatory site (distinct from the classical inhibitory glycine site) is closely associated with the NMDA receptor; glycine is required for channel activation and enhances NMDA responses. $\mathrm{Mg}^{2+}$ blocks the channel in a voltage-dependent manner; at relatively negative membrane potentials $\mathrm{Mg}^{2+}$ blocks the channel and blockade is relieved by depolarization. Thus NMDA receptor channel activation requires both NMDA and glycine receptor activation and concomitant membrane depolarization. Also, $\mathrm{Zn}^{2+}$ reduces NMDA responses by binding to a site on the external face of the membrane (not illustrated). NMDA responses can be blocked pharmacologically in at least 3 ways: competitive NMDA antagonists, such as CPP, compete for binding at the NMDA recognition site; competitive glycine receptor antagonists, such as HA-966, block the glycine site and reduced NMDA mediated responses; and non-competitive NMDA receptor antagonists such as MK-801 and dissociative anesthetics bind within the ionophore to the $\mathrm{PCP}$ receptor and prevent inn fluxes.

\section{TABLE I}

Specific and non-specific agonists and antagonists of EAA-receptor subrypes

Non-specific compounds non-selectively interact with all EAA receptor subtypes. Abbreviations: NMDA, $N$-methyl-D-aspartate; AMPA, $a$-amino-3-hydroxy-5-methyl-4-isoxazole proprionate; APV, D-2-amino-5-phosphonovalerate; CPP, 3- $[( \pm)-2$-carboxypiperazine-4-yllpropyl-1-phosphonate; HA-966, 1-hydroxy-3-amino-pyrrolidone-2; MK-801, (+)-5-methyl-10,11-dihydro-5H-dibenzo [a,d] cyclohepten-5,10-imine; PCP, phencyclidine; CNQX (FG9065), 6-nitro,7-cyanoquinoxaline-2,3-dion; DNOX (FG9041), 6,7-dinitroquinoxaline-2,3-dion; DGG, $\gamma$-D-glutamylglycine.

\begin{tabular}{|c|c|c|}
\hline & \multicolumn{2}{|c|}{ Excitatory amino acid receptor subtypes } \\
\hline & NMDA & non-NMDA \\
\hline \multicolumn{3}{|l|}{ Specific agonists } \\
\hline glycine site & $\begin{array}{l}\text { NMDA } \\
\text { L-aspartate* } \\
\text { quinolinate }^{*} \\
\text { homocysteate* } \\
\text { glycine* }^{*}\end{array}$ & $\begin{array}{l}\text { quisqualate } \\
\text { AMPA } \\
\text { kainate }\end{array}$ \\
\hline Non-specific agonists & L-glutamate* & L-glutamate* \\
\hline \multicolumn{3}{|l|}{ Specific antagonists } \\
\hline NMDA site & $\begin{array}{l}\text { D-APV } \\
\text { CPP } \\
\text { CGS-19775 }\end{array}$ & CNOX, DNOX** \\
\hline $\begin{array}{l}\text { glycine site } \\
\text { channel }\end{array}$ & $\begin{array}{l}\text { HA-966 } \\
\text { MK-801 } \\
\text { PCP } \\
\text { ketamine }\end{array}$ & \\
\hline Non-specific antagonists & $\begin{array}{l}\text { DGG } \\
\text { kynurenate }{ }^{*, * *}\end{array}$ & $\begin{array}{l}\text { DGG } \\
\text { kynurenate }^{*}\end{array}$ \\
\hline
\end{tabular}

- Indicates compounds that are endogenous to mammalian brain.

** Note CNQX, DNQX and kynurenate also antagonize the glycine modulatory site associated with the NMDA receptor at high micromolar concentrations.

subtypes, the synthetic analogue NMDA and the endogenous EAAs, aspartate, homocysteate and quinolinate, selectively activate NMDA receptors ${ }^{54,69,223}$. A great deal of information about the regulation of NMDA receptors has emerged recently with the discovery of potent and selective ligands. The NMDA receptor is linked to a calcium permeable cationic channel that is blocked by magnesium in a voltage-dependent manner

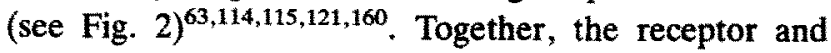
channel comprise a receptor/channel complex that includes several regulatory sites. Glycine is required for receptor/channel activation and potentiates NMDA responses by binding to a closely associated site $^{95,102}$. MK-801 and dissociative anesthetics block NMDA responses, in a use-dependent fashion, by binding to the phencyclidine site within the open channel ${ }^{100,117} \cdot \mathrm{Zn}^{2+}$ and polyamines also regulate receptor/channel activity at sites distinct from those described above ${ }^{179,186,241}$. Table $I$ lists the most commonly used agonists and antagonists 

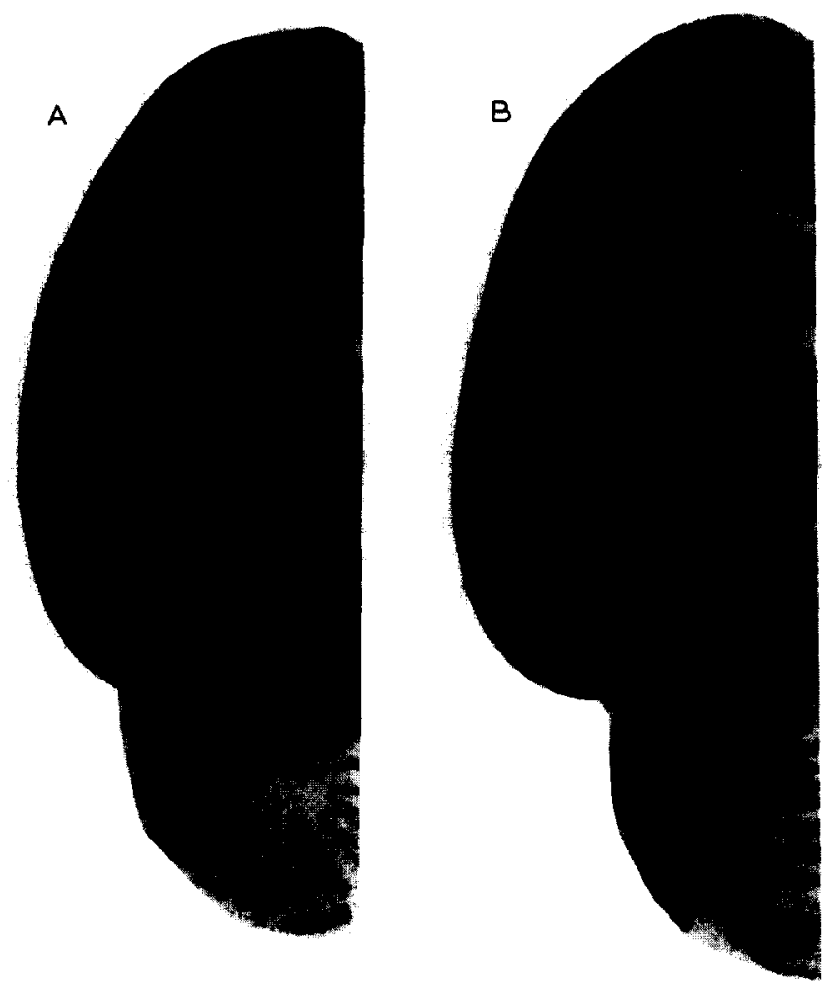

Fig. 3. Comparison of the distribution of (A) NMDA and (B) quisqualate-sensitive $\left[{ }^{3} \mathrm{H}\right]$ glutamate binding in horizontal brain sections from PND 7 rats. NMDA receptors were labeled with 40 $\mathrm{nM}\left[{ }^{3} \mathrm{H}\right]$ glutamate in $50 \mathrm{mM}$ Tris-acetate $\left(\mathrm{pH} 7.2\right.$ at $\left.4{ }^{\circ} \mathrm{C}\right)$ containing $2.5 \mu \mathrm{M}$ quisqualate ${ }^{78,134}$. Quisqualate receptors were labeled with $40 \mathrm{nM}\left[{ }^{3} \mathrm{H}\right]$ glutamate in $50 \mathrm{mM}$ Tris- $\mathrm{HCl}\left(\mathrm{pH} 7.2\right.$ at $\left.4{ }^{\circ} \mathrm{C}\right)$ containing $2.5 \mathrm{mM} \mathrm{CaCl}_{2}$ and $100 \mu \mathrm{M} \mathrm{NMDA}^{.8}$

\section{TABLE II}

Synaptic markers of EAA pathways that are transiently overexpressed during development

\begin{tabular}{|c|c|c|c|}
\hline Region & Marker & $\begin{array}{l}\text { Maximal } \\
\text { expression }\end{array}$ & $\begin{array}{l}\text { Refer- } \\
\text { ence }\end{array}$ \\
\hline \multirow[t]{3}{*}{ Visual cortex } & $\begin{array}{l}\mathrm{Na}^{+} \text {-independent } \\
{\left[{ }^{3} \mathrm{H} \mid \text { glutamate binding }\right.}\end{array}$ & PND $15^{1}$ & 201 \\
\hline & [ $\left.{ }^{3} \mathrm{H}\right]$-D-aspartate uptake & PNW 6- $7^{2}$ & 65 \\
\hline & $\begin{array}{l}\text { APV-sensitive } \\
{\left[{ }^{3} \mathrm{H}\right] \text { glutamate binding }}\end{array}$ & PNW 4-12 & 21 \\
\hline Frontal cortex & $\begin{array}{l}\text { NMDA-sensitive } \\
{\left[{ }^{3} \mathrm{H} \text { ]glutamate binding }\right.}\end{array}$ & PNY $1-2^{3}$ & 105 \\
\hline Entorhinal cortex & $\begin{array}{l}\text { NMDA-sensitive } \\
{\left[{ }^{3} \mathbf{H}\right] \text { glutamate binding }}\end{array}$ & PND 7-21 ${ }^{1}$ & 134 \\
\hline Hippocampus & $\begin{array}{l}\mathrm{Na}^{+} \text {-independent } \\
{\left[{ }^{3} \mathrm{H} \text { lglutamate binding }\right.}\end{array}$ & PND9 $^{1}$ & 13 \\
\hline \multirow[t]{2}{*}{ CAl subfield } & NMDA-sensitive & PND 14-28 ${ }^{1}$ & 134 \\
\hline & {$\left[{ }^{3} \mathrm{H}\right]$ glutamate binding } & PND 4-13 ${ }^{1}$ & 231 \\
\hline CA3 subfield & $\begin{array}{l}\text { NMDA-sensitive } \\
{\left[{ }^{3} \mathrm{H}\right] \text { glutamate binding }}\end{array}$ & PND 10-28 & 134 \\
\hline Globus pallidus & $\begin{array}{l}\text { quisqualate-sensitive } \\
{\left[{ }^{3} \mathrm{H}\right] \text { glutamate binding }}\end{array}$ & PND $7^{1}$ & 80 \\
\hline
\end{tabular}

Superscript numbers refer to the experimental subject:

rat (PND = postnatal day);

${ }^{2}$ cat $(\mathrm{PNW}=$ postnatal week $)$;

${ }^{3}$ human (PNY = postnatal year). of NMDA receptors and their site of action as well as endogenous ligands.

\subsection{Non-NMDA receptors}

Non-NMDA receptors are traditionally divided into quisqualate and kainate receptors based on their preferential physiological responses to alkaloid agonists. Subtypes of quisqualate receptors have been delineated by their linkage to $\mathrm{Na}^{+}$-conducting channels (ionotropic site) or phosphoinositol (PI) hydrolysis (metabotropic site) ${ }^{157,214,239}$. The ionotropic site is selectively activated by $\alpha$-amino-3-hydroxy-5-methyl-4-isoxazole propionate (AMPA) and mediates fast synaptic responses. The metabotropic site is insensitive to AMPA and produces a delayed long-lasting response by stimulating PI metabolism leading to second messenger generation and mobilization of intracellular calcium ${ }^{157,214}$. Selective endogenous agonists of quisqualate and kainate receptors have not been described and these sites share a common antagonist profile ${ }^{239}$. Each glutamate receptor subtype has a unique distribution in the brain with highest levels generally present in cortex, basal ganglia and hippocampus and with lowest levels found in the hindbrain (see Fig. 3$)^{78,134,136,145}$.

\section{ONTOGENY OF EAA PATHWAYS}

The development of putative EAA pathways have been examined using a combination of experimental techniques: electrophysiology, assay of high-affinity up-

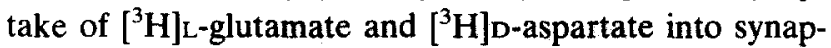
tosomes, immunocytochemistry and receptor-binding techniques. High-affinity uptake of $\left[{ }^{3} \mathrm{H}\right]$ glutamate into synaptosomes and immunocytochemistry have been used to label presumptive presynaptic neurons and terminals whereas electrophysiological and receptor-binding studies predominantly have focused on the post-synaptic components of these pathways (Fig. 1). These techniques have demonstrated major ontogenic alterations in EAA pathways. Transient overproduction of EAA synaptic terminals appears to be common during development and these overshoots relate temporally to periods of heightened synaptic plasticity and consolidation of synaptic connections (Table II). This section reviews the ontogeny of EAA synaptic markers with a focus on receptorbinding studies. The majority of studies have examined the development of these markers in visual and associated cortical areas, hippocampus and basal ganglia of rats and cats. Several human studies will also be discussed. Also, developmental changes in EAA-stimulated phosphatidyl inositol metabolism and in the physiology of EAA systems will be reviewed. 


\subsection{Visual associated structures}

Glutamate may be the primary neurotransmitter in visual pathways to cortex ${ }^{232}$. Development of EAA pathways in the visual system has been studied in some detail. High affinity $\mathrm{Na}^{2+}$-dependent synaptosomal uptake of $\left[{ }^{3} \mathrm{H}\right]$ glutamate in visual cortex and lateral geniculate body of developing rats increases continuously from birth and plateaus at adult levels by PND 15 and 20, respectively ${ }^{106}$. At PND 2 uptake is $30 \%$ of adult levels. $\mathrm{Na}^{+}$-independent $\left[{ }^{3} \mathrm{H}\right]$ glutamate binding, which nonselectively labels all glutamate receptor subtypes but not uptake sites, in the visual cortex, lateral geniculate and superior colliculus transiently peaks at approximately PND $15^{201}$. Binding (expressed as mol/weight protein) increases by $30-50 \%$ from PND 10 to PND 15 and rapidly declines (by up to a factor of 10 ) to plateau at adult levels by PND 25 .

Similar developmental profiles of high-affinity $\left[{ }^{3} \mathrm{H}\right]_{\mathrm{D}-}$ aspartate uptake occur in the same visual structures in kittens ${ }^{65}$. In cortical areas 17 and 18, D-aspartate uptake (expressed as mol-weight protein ${ }^{-1} \cdot$ time $^{-1}$ ) reaches adult levels between postnatal weeks (PNW) 1 and 2. PNW 6-7 values exceed adult values approximately 3-fold. Uptake values decline from PNW 10 to PWN 17 but are still 80\% above adult values. Developmental profiles of uptake in the lateral geniculate and superior colliculus are similar although peak uptake is delayed by approximately 3 weeks in the lateral geniculate, whereas uptake rises sharply in the superior colliculus with peak levels occuring during PNW 3.

Furthermore, Bode-Greuel and Singer ${ }^{21}$ have recently shown that development of APV (2-amino-5-phosphonovalerate)-sensitive $\left[{ }^{3} \mathrm{H}\right.$ ]glutamate binding to NMDA receptors in the primary visual cortex of kittens parallels the time course of the critical period when the visual cortex is susceptible to experience-dependent modifications ${ }^{174}$ : binding increases 2.5 -fold from adult densities at PNW 2 to PNW 4, plateaus through PNW 12 and then declines to adult (more than 100 weeks old) densities by PNW 17 (see subsection 6.2). These developmental changes of APV-sensitive $\left[{ }^{3} \mathrm{H}\right]$ glutamate binding sites were qualitatively similar in all cortical layers. Absolute binding densities were greatest in supragranular layers (I-III), intermediate in layer IV (where the geniculocortical fibers terminate) and lowest in infragranular layers (V, VI). The APV-insensitive component of $\left[{ }^{3} \mathrm{H}\right]$ glutamate binding, which presumably represents non-NMDA receptor binding, did not change during the same period of development. Dark rearing, which prolongs the period during which functional changes can be induced by monocular depreviation $^{52 a}$, does not prolong the transient enhancement of APV-sensitive $\left[{ }^{3} \mathrm{H}\right]$ glutamate binding. These results suggest that some other mechanism besides or in conjunction with reduction of NMDA receptors is involved in the termination of the physiologically defined critical period for ocular dominance plasticity.

The sharp decline in glutamatergic pathway markers following the transient overshoot observed in these visual structures correlates with periods of synaptic elimination and stabilization of functional synapses. Taken together, the results indicate that these EAA pathways undergo striking developmental changes, involving transient overshoots, especially during 'critical' periods of visual development and further suggest that EAA neurotransmitter pathways may play a role in modifying neuronal plasticity during these developmental periods (see Sections 5 and 6). For instance, NMDA receptors appear to be more effective in the visual cortex of kittens, during the critical period of visual development, compared to adults ${ }^{67,233}$. Also, the developmental period of overexpression of NMDA-sensitive glutamate binding parallels the critical period when visual experience can modify the columnar organization of inputs to the visual cortex (see subsection 6.2).

\subsection{Non-visual cortical areas}

EAA synaptic markers in non-visual cortical areas also change markedly during development. In rat brain membranes prepared from entire cerebral cortices, $\mathrm{Na}^{2+}$. independent glutamate binding (expressed as mol bound per cortex) to post-synaptic glutamate receptors rises sharply from PND 5 (3\% of adult values) to PND 20 (50\% of adult values) followed by a more gradual rise to adult levels which plateau between PND 40 and 50. In contrast, $\mathrm{Na}^{2+}$-dependent $\left[{ }^{3} \mathrm{H}\right]$ glutamate binding, to presumptive presynaptic glutamate sites, rises very slowly from PND 5 to PND 30 (8\% of adult binding) and then rapidly increases to maximal levels at PND 50, suggesting that development of presynaptic markers may lag behind development of post-synaptic sites ${ }^{196}$. However, the interpretation of $\mathrm{Na}^{+}$-dependent $\left[{ }^{3} \mathrm{H}\right]$ glutamate binding is complicated by the unknown contribution of glial uptake binding sites relative to presynaptic neuronal uptake sites. An overshoot of binding to NMDA recognition sites occurs in the temporal cortex of rats. NMDA-sensitive $\left[{ }^{3} \mathrm{H}\right]$ glutamate binding to rat brain sections (expressed as mol/weight protein) rises gradually from PND 1 to plateau at adult levels by PND 28 (ref. 134). The developmental profile of binding to individual cortical layers is similar although maximal binding occurs in cortical layers I and II. A similar developmental overshoot of binding to NMDA receptors has been observed in human frontal cortex: binding densities (pmol/mg protein) increase sharply during the early postnatal period and transiently peak between age 1 and 2 years, then, after age 10 years, decrease by $9 \% /$ 
decade $^{105}$. These developmental changes in NMDA receptor binding roughly parallel synaptogenesis in human frontal cortex ${ }^{91}$.

\subsection{Hippocampal formation}

An early overshoot in the expression of glutamate binding sites is observed during postnatal development in rat hippocampus ${ }^{13}$. At PND 4, $\mathrm{Na}^{2+}$-independent $\left[{ }^{3} \mathrm{H}\right]-$ glutamate binding (expressed as $\mathrm{mol} /$ weight protein) to post-synaptic sites represents $30 \%$ of adult values and then rises rapidly from PND 4 and transiently peaks at PND $9(160 \%$ of adult values) after which binding gradually decreases and plateaus at adult values by PND 23. These developmental changes appear to reflect alterations in the number of binding sites, since the affinity of these sites does not change between PNDs 4 , 9 and $23^{13}$. The rapid increase in glutamate binding sites coincides with the development of afferent input and elaboration of dendrites in the hippocampus ${ }^{47,112,180,181}$. The abrupt overshoot of glutamate receptor binding at PND 9 correlates with the developmental onset of long-term potentiation, an electrophysiological correlate of learning and memory (see subsection 6.1) and with the ability of calcium to stimulate $\left[{ }^{3} \mathrm{H}\right]$ glutamate binding ${ }^{13}$. In contrast, the developmental profile of $\mathrm{Na}^{2+}$-dependent high-affinity uptake of $\left[{ }^{3} \mathrm{H}\right]$ glutamate (which appears to represent neuronal uptake) in rat brain sections increases linearly from PND 0 through PND $50^{202}$. The developmental lag between post-synaptic glutamate receptor binding and high-affinity uptake of glutamate is very similar to the development of these parameters in cerebral cortex.

Results of studies using in vitro autoradiography demonstrate marked overexpression of NMDA-type glutamate receptors in the hippocampal formation during postnatal development. Tremblay et al. ${ }^{231}$ demonstrated that both total $\mathrm{Na}^{+}$-independent $\left[{ }^{3} \mathrm{H}\right]$ glutamate binding and NMDA-sensitive $\left[{ }^{3} \mathrm{H}\right.$ ]glutamate binding in rat brain sections transiently exceed adult densities by up to 2 -fold between PND 4 to PND 13 in stratum radiatum of CA1 in rats and find a similar developmental pattern in developing human brain ${ }^{191}$. Also, the developmental profile of NMDA-sensitive $\left[{ }^{3} \mathrm{H}\right]$ glutamate binding varies between individual rat hippocampal subfields ${ }^{134}$. NMDA-sensitive $\left[{ }^{3} \mathrm{H}\right.$ ]glutamate binding exceeds adult levels by $50 \%$ to $120 \%$ in all hippocampal regions examined with peak densities generally occurring between postnatal days (PND) 10 and 28. In stratum radiatum CA1 binding increases slowly from $49 \%$ to $61 \%$ of the adult value between PND 1 and 7. Then, binding rapidly rises and exceeds adult values by $51 \%$ at PND 14, remains elevated through PND 28 and then decreases to adult levels (Fig. 4). The ontogenic profile of NMDA recognition site binding is similar in other hippocampal regions although the initial age of maximal binding and period of stabilization varies. NMDA receptor binding in area $\mathrm{CA} 3$ develops more rapidly than in area $\mathrm{CA} 1$ with maximum levels reached by PND 10, which is consistent with the earlier development of afferent input to area $\mathrm{CA}^{113}$. However, the ontogeny of NMDA-sensitive $\left[{ }^{3} \mathrm{H}\right]$ glutamate binding to NMDA recognition sites does not parallel the development of two other receptor components of the NMDA receptor channel complex (strychnine-insensitive $\left[{ }^{3} \mathrm{H}\right]$ glycine binding to the glycine modulatory site and $\left[{ }^{3} \mathrm{H}\right] \mathrm{TCP}$ binding to the PCP receptor within the NMDA-associated ionophore). The ontogenic profiles of glycine modulatory site binding and PCP receptor binding are nearly identical. However, development of binding to these sites is delayed with respect to NMDA recognition site binding. The rapid rise in binding observed between PND 7 and PND 14 with NMDA receptors in stratum radiatum $C A 1$ is contrasted by a much slower rise in glycine and PCP receptor binding. Furthermore, maximal glycine and PCP receptorbinding densities are not reached until PND 28 and are lower than NMDA recognition site binding densities ${ }^{134}$.

The observed developmental patterns of binding to each of the receptor components of the NMDA receptor channel/complex are consistent with postnatal changes in cytoarchitecture, synaptogenesis, afferent lamination and functional development of the hippocampus. For instance, the abrupt increases in NMDA receptor binding occurring during the second PNW coincides with the development of LTP and the expression of synaptic connections in this region ${ }^{13,87,113,180}$. These findings are noteworthy, since NMDA receptor activation is required for induction of LTP (sce subsection 6.1) ${ }^{158}$. However, the relative overexpression of NMDA recognition sites with respect to glycine and PCP receptors between PND 7 and PND 21 suggests that there is differential regulation of the expression of these receptor components during development. These findings support the hypothesis that multiple genetic forms of NMDA receptor complexes may exist ${ }^{224}$.

\subsection{Non-NMDA receptors in selected areas}

Greenamyre et al ${ }^{80}$ reported transient expression of quisqualate-sensitive glutamate receptors in the globus pallidus of developing rats concurrent with increased high-affinity synaptosomal uptake of glutamate. $\left[{ }^{3} \mathrm{H}\right]-$ Glutamate binding in the globus pallidus increased approximately 3-fold from PND 1 to maximal levels at PND 7 ( $7.5 \mathrm{pmol} / \mathrm{mg}$ protein). Binding levels decreased 3 -fold over the next 3 weeks to achieve adult densities by PND $28(1.8 \mathrm{pmol} / \mathrm{mg}$ protein $)$. No transient peak in NMDA receptor binding was observed in the globus 


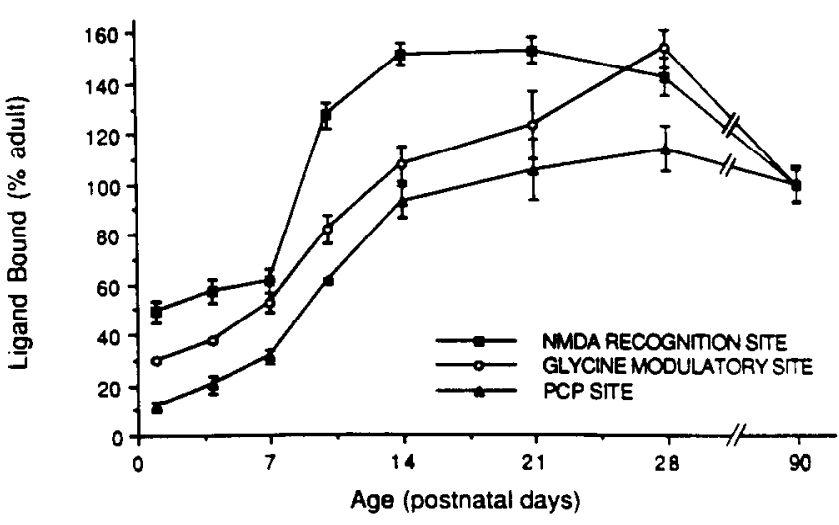

Fig. 4. Comparison of postnatal developmental profiles of NMDAsensitive $\left[{ }^{3} \mathrm{H}\right]$ glutamate binding to NMDA recognition sites, strychnine-insensitive $\left[{ }^{3} \mathrm{H}\right]$ glycine binding to glycine modulatory sites and $\left[{ }^{3} \mathrm{H}\right] \mathrm{TCP}$ binding to PCP receptors in stratum radiatum of the CAI hippocampal subfield. Each data point represents the relative binding densities (mean \pm S.E.M.) compared with binding densities in corresponding areas in adult rats (adult $=$ PND 90). Four animals were used at each age (except PND 21, $n=3$ ). Vertical error bars represent S.E.M.

pallidus. Binding in the striatum paralleled globus pallidus binding from PND 1 to PND 7 but then remained elevated throughout development. In human fetal and early postnatal brain, a transient developmental expression of these receptor sites in the globus pallidus, the subthalamic nucleus and the substantia innominata also occurs $^{12,80}$. It is possible that transient expression of the putative EAA pathway to globus pallidus may regulate synaptic organization within the globus pallidus, since glutamate, via actions at non-NMDA type glutamate receptors, influences dendritic arborization and synaptogenesis $^{118-120}$.

Developmental alterations in high-affinity kainate binding sites have also been demonstrated. In the adult rat brain the highest density of $\left[{ }^{3} \mathrm{H}\right]$ kainate binding sites is present in stratum lucidum of hippocampal area CA3 and these sites are believed to be, in part, on mossy fiber terminals projecting to this area ${ }^{19,144,235}$. In rat hippocampus $\left[{ }^{3} \mathrm{H}\right]$ kainate binding remains relatively low $(40 \%$ of adult values) between PND 3 and PND 12 and then rises rapidly (2-fold) to plateau at adult values by PND $17^{15}$. In contrast, binding to amygdala and piriform membranes remains stable between PND 3 and PND 17 and then rises (1.5-fold) rapidly to adult levels by PND 22. The developmental rise in kainate binding sites in amygdala from PND 17 to 22 may account for the unique developmental expression of kainate-induced limbic seizures ${ }^{15}$. A transient high density of high-affinity $\left[{ }^{3} \mathrm{H}\right]$ kainate binding sites has been reported in the supragranular layer of the fascia dentata of the hippocampus in humans during development and may be related to alterations in synaptic connections, since mossy fibers have a great capacity to form synaptic rearrangements in this zone $e^{68,109,150,151,185,190,246}$. High affinity $\left[{ }^{3} \mathrm{H}\right]$ kainate binding in rodent striatum rises 10 -fold from 2 to 6\% of adult values at PND 4-7 to PND 21. By PND 28 receptor densities are $80 \%$ of adult levels. This developmental profile of post-synaptic kainate sites corresponds with the development of glutamatergic innervation to the striatum and development of kainateinduced brain injury ${ }^{28}$.

\subsection{EAA-stimulated phosphatidyl inositol hydralysis}

In addition to the ionophore-associated EAA receptors, a subset of quisqualate-type EAA receptors are coupled with phospholipase $C$ and receptor activation stimulates phosphatidyl inositol turnover (Fig. 1). Activation of these receptors results in hydrolysis of phosphatidyl-4,5-inositolbisphosphate $\left(\mathrm{PIP}_{2}\right)$ and generation of second messengers ( $\mathrm{IP}_{3}$ and DG). Glutamate and its analogues ibotenate and quisqualate stimulate inositol phospholipid metabolism maximally in the immature brain ${ }^{156}$. In both rat hippocampus and neocortex, EAAstimulated phosphoinositide hydrolysis transiently peaks at PND 6 (1000 times the response at PND 35) and declines during postnatal development to negligible levels by PND 35. Although glutamate has little direct effect on inositol phospholipid metabolism in adult animals, it inhibits norepinephrine-stimulated inositol phospholipid turnover in a dose-dependent fashion.

The role of enhanced EAA-mediated inositol phospholipid breakdown in development is unclear. However, several indirect lines of evidence suggest that this second messenger system may regulate some forms of developmental plasticity through activation of phospolipid-dependent enzymes and intracellular calcium mobilization. The developmental transient expression of EAA-stimulated phosphoinositide hydrolysis in rat brain corresponds roughly with developmental periods of heightened synaptic plasticity. Furthermore, Dudek and Bear $(1989)^{55 a}$ reported that the developmental transient expression of ibotenate (a glutamate analogue)-stimulated phosphoinositide hydrolysis in kitten striate cortex parallels postnatal changes in cortical susceptibility to the effects of visual deprivation. Ibotenate $(10 \mu \mathrm{m})$-stimulated phosphoinositide turnover in striate cortex was 30\% greater than PNW 16 values at PNW 3 and transiently peaked at PNW 5 (approximately 3 times greater than adult values), then rapidly decreased to PNW 16 values by PNW 12. Glutamate, but not the selective EAA agonists NMDA or AMPA, elicited a similar developmental profile of phosphoinositol turnover. The developmental pattern of ibotenate-stimulated phosphoinositol turnover was nearly identical to previous estimates of the critical period of sensitivity of binocular connections 
in kitten striate cortex to eyelid suture during postnatal development ${ }^{174}$. However, stimulation of phosphoinositol hydrolysis by the cholinergic agonist carbachol (100 $\mu \mathrm{m}$ ) was equally effective at all postnatal ages during the critical period, which suggests that the enhanced phosphoinositide turnover during the critical period of visual development is specific to EAA-linked mechanisms (i.e. ibotenate recognition site). Furthermore, the transient increase in ibotenate-stimulated phosphoinositide turnover at PNW 5 did not occur in the visual cortex of dark-reared kittens in which the critical period for experience-dependent synaptic modifications is postponed. However, stimulation by carbachol was not altered by a similar visual deprivation, which suggests that dark-rearing had a selective effect on EAA-stimulated phosphoinositide hydrolysis. Furthermore, several other forms of plasticity are associated with enhanced inositol phospholipid turnover. In adult rats lesions of putative EAA hippocampal pathways selectively enhance EAA-stimulated inositol phospholipid responses ${ }^{157 a}$. Hypoxia-ischemia and EAA-induced brain injury preferentially enhance quisqualate-stimulated phosphoinositide turnover ${ }^{33 a, 33 b}$. Similar findings have been reported in adult rat brain slices following electrically induced amygdala kindling ${ }^{91 a}$.

Given the theoretical interactions between second messenger systems coupled to NMDA and non-NMDA receptors, the dependence of synaptic modifications upon post-synaptic $\mathrm{Ca}^{2+}$ conductances mediated by NMDA associated ionophores and the relatively prolonged response of phosphoinositol turnover, it is likely that developmental expression of EAA-stimulated phosphoinositol hydrolysis may act to modulate the developmental capacity for synaptic modifications by setting the threshold necessary for these changes through a variety of mechanisms ${ }^{176 a}$. Detailed examination of the synaptic mechanisms which contribute to the transiently enhanced EAA-stimulated phosphoinositol turnover will have broad implications with regard to the role of EAAstimulated phosphoinositol hydrolysis in normal development, acute brain injury and CNS regeneration during development.

\subsection{Physiological changes}

The ontogeny of EAA synaptic markers relates to several developmental changes in the physiology of EAA receptors. Post-synaptic excitation relative to inhibition predominates during the first postnatal weeks of life in rodents as does enhanced seizure susceptibility ${ }^{81,86,87}$, 183,204,226. In area CA3, superfusion of NMDA elicits recurrent synchronized burst activity; the epileptogenic effect of NMDA increases from PND 1 and is maximal at PND $10^{101}$. Furthermore, in PND 1-8 rats, $85 \%$ of
CA3 hippocampal neurons exhibit NMDA receptor regulated spontaneous giant depolarizing potentials whereas in PND 9-12 rats only 48\% of the neurons exhibit this characteristic and this response disappears after PND 12 (ref. 17a). Also, the susceptibility of hippocampal area CA3 to convulsant-induced epileptiform activity is greater in immature (smaller than PND 7) rodent brain than more mature brain (greater than PND $14)^{226}$. Recurrent excitatory synaptic pathways appear to play a key role in the generation of epileptiform discharges in the hippocampus ${ }^{141,142}$. These synapses utilize EAAs as their neurotransmitters ${ }^{42}$. In fact, specific NMDA receptor antagonists block this seizure activity $^{25}$. These developmental changes in seizure susceptibility have been related to enhanced degrees of excitatory synaptic interaction resulting from an abundance of recurrent excitatory synaptic connections in the hippocampus early in development ${ }^{216}$. The delayed postnatal development of functional inhibitory circuits is also likely to contribute to these effects ${ }^{86,204}$.

Ontogenic changes in the voltage dependence of the NMDA receptor complex may also be related to these changes. Although superfusion of NMDA to area CA3 pyramidal neurons evokes similar peak currents in immature (PND 0-10) and adult rats, NMDA currentvoltage relations do not consistently exhibit a region of negative slope conductance (which is characteristic of adults) in immature animals ${ }^{16}$. This change in the voltage dependency of the NMDA receptor/channel may reflect alterations in the ability of magnesium to block the NMDA receptor associated ionophore. In fact, Brady and $S w a n n^{26}$ have suggested that the immature NMDA receptor channel/complex is less sensitive to blockade by magnesium and more sensitive to calcium blockade than its mature counterpart. Reduction of the extracellular concentration of calcium from $2 \mathrm{mM}$ to $1 \mathrm{mM}$ reduces the voltage sensitivity of NMDA responses in immature slices (PND 9-19) but not in adult slices. These alterations in divalent cation sensitivity may underlie observed developmental changes in the susceptibility of the brain to seizures and excitotoxicity (see Section 8 ).

Developmental changes also occur in the chemosensitivity of neurons to EAAs. Rodent CA1 stratum radiatum pyramidal neurons respond maximally to iontophoresis of NMDA between PND 12 and 31 (ref. 83). This response corresponds closely with the period of overproduction of NMDA receptors in this area ${ }^{134}$. Furthermore, responses of cerebellar granule and Purkinje cells to NMDA change markedly during development. In contrast to quisqualate and kainate responses which do not change during development, granule and Purkinje cell responses to NMDA exceed adult levels by $100 \%$ at PND 8 and rapidly declined between PND 14 and 21 (ref. 71). 
The peak sensitivity to NMDA at PND 8 corresponds with the functional development of the excitatory climbing fibre-Purkinje cell and mossy fiber-granule cellPurkinje cell circuits within the cerebellar cortex ${ }^{2,3}$. Since NMDA receptors play a role in use-dependent synaptic modifications, developmental changes in this receptor system may function in the synaptic organization of the above neuronal circuits during cerebellar development (see Section 6).

Recent studies have examined the ontogenic changes in the role of NMDA receptors in normal sensory processing in kitten visual cortex and these studies suggest that, depending on the cortical layer, NMDA receptor activation may make the greatest contribution to EAA synaptic transmission during the critical developmental period of ocular dominance plasticity ${ }^{67 a, 233}$. Initially, Tsumoto et al. ${ }^{233}$ demonstrated that the number of visual cortical cells with visual responses significantly suppressed by iontophoresis of the specific NMDA antagonist APV were greater in kittens (ages 4-8 weeks) during the critical period ( $71 \%$ suppressed) than in adult cats (33\% suppressed) whereas equal sensitivity was observed between groups to iontophoresis of the broad acting EAA antagonist kynurenate. Furthermore, the mean current intensity required for APV to exert its full action was significantly smaller in kittens than in adults while the minimum current intensity for NMDA needed to excite visual cortical cells was significantly lower in kittens compared to adults. In contrast, quisqualate was equally effective in exciting cells in kitten and adult visual cortex. These observations suggest that NMDA receptors are more effective in generating visual responses during the critical period of ocular dominance plasticity in kittens than in adult cats. More recently, Fox et al. ${ }^{67 a}$ have extended these observations by examining the role of NMDA receptors in both visual responses and spontaneous activity in the visual cortex as a function of age and cortical layer. In the granular and deep cortical layers (IV-VI), D-APV iontophoresis markedly reduced visual responses of kittens but only spontaneous activity in adults; visual responses were reduced by $50 \%$ in kittens 3 weeks of age, $25 \%$ at 4 weeks and were not significantly affected in adults. In contrast, visual responses in supragranular layers (II and III) were more sensitive to suppression by D-APV than layers IV-VI, but this effect was independent of age. The critical period of visual plasticity in granular and infragranular layers and the period of segregation of geniculocortical afferents in layer IV is roughly correlated with the period during which NMDA receptors exert a maximal influence on visual responses in these layers. These temporal correlations suggest that NMDA receptors may play a role in the developmental plasticity of the visual cortex.
In summary, pre- and post-synaptic markers of putative EAA pathways undergo marked changes during development. Transient overshoots of EAA synaptic markers are common, occur during restricted periods of development and are present in multiple brain regions in rats, cats and humans (Table II). Several of these changes occur during 'critical' periods of CNS development and correspond with periods of heightened synaptic plasticity. These changes in EAA pathways also relate to alterations in neuronal plasticity. EAAs may influence neuronal development through a variety of receptor/channel/ second messenger-related actions. Furthermore, the electrophysiological and biochemical characteristics of EAA receptors change during development. Finally, since these neurotransmitter systems appear to be very active during restricted developmental periods and contribute to regulation of several forms of synaptic plasticity and neuroarchitecture, it is possible that EAA pathways play an important regulatory role in the normal development of neuronal circuitry (see Sections 5 and 6).

\section{PROMOTION OF NEURONAL SURVIVAL, GROWTH AND DIFFERENTIATION}

In addition to the role of EAAs in neurotransmission, EAAs may also serve a neurotrophic function during development. Evidence suggests that EAAs have trophic influences on differentiating neurons and regulate development of neuronal cytoarchitecture. Furthermore, EAAs may participate in the formation of neuronal circuitry and in synaptic plasticity.

Neurons require specific trophic factors during defined developmental time windows to promote their viability ${ }^{44}$, ${ }^{50,82}$. In addition to neurotrophic factors such as nervegrowth factor and related peptides, neurotransmitters released from nerve terminals also have trophic properties. Exogenously applied NMDA promotes cell survival in cerebellar granule cell cultures in a dose-dependent fashion ${ }^{9,10}$. Concentrations of NMDA ranging from 35 to $140 \mu \mathrm{M}$, but not ibotenate or quinolinate, prevent the extensive loss of granule cells that normally occurs in the presence of low extracellular concentrations of $\mathrm{K}^{+}$. The trophic influences of NMDA appear to be mediated by NMDA receptors, since addition of the competitive NMDA receptor antagonist, 2-amino-5-phosphonovalerate(APV), blocks the effect of NMDA. Other types of NMDA antagonists including dextromethorphan and MK-801 can reproduce this effect. Activation of nonNMDA receptors does not affect granule cell survival but does promote synaptogenesis in other experimental systems ${ }^{119}$. The trophic effect of NMDA is dependent both on the degree of membrane depolarization and the developmental stage of the neurons; the effect develops 
between 2 and 4 days in vitro and is mimicked by raising the extracellular concentration of $\mathrm{K}^{+}$to $25 \mathrm{mM}$. $\mathrm{Ca}^{2+}$ entry through NMDA receptor associated channels, and/or voltage-sensitive $\mathrm{Ca}^{2+}$ channels (produced by depolarization in $25 \mathrm{mM} \mathrm{K}^{+}$-containing medium) probably underlies the trophic effects of NMDA on granule cells, since neuronal survival is dependent on the concentration of extracellular $\mathrm{Ca}^{2+}$. The requirement of NMDA to promote granule cell survival over a narrow 2-3-day developmental period corresponds to the same time that differentiating granule cells migrate to the internal granule layer and receive glutamatergic input in vivo $^{3}$. The developmental dependence on NMDA appears to generalize to other cell populations as well, since NMDA has been demonstrated to enhance neuronal survival in dissociated spinal cord cultures ${ }^{153}$. The possibility that inositol phospholipid hydrolysis may contribute to the observed trophic effects of NMDA on cultured cerebellar granule cells needs to be addressed, since inositol phospholipid responses to NMDA are particularly potent in cerebellar granule cell cultures ${ }^{157}$.

L-Glutamate also has trophic properties. Supplementation of cultures of dissociated neurons (18 days in vitro) from whole brain of 15-day-old rat fetuses with $5 \mu \mathrm{M}$ L-glutamate, but not the electrophysiologically and metabolically inactive $\mathrm{D}$-isomer, promotes neuronal growth and produces associated maturational cytological changes ${ }^{7}$. Compared to control cultures, L-glutamate treatment increases overall neuronal and nuclear size by $14 \%$ and $33 \%$, respectively. Mitochondria, free ribosomes and rough endoplasmic reticulum are more abundant in $\mathrm{L}$-glutamate exposed neurons whereas the number of Golgi apparatuses are comparable to neurons in control cultures. These findings indicate an increased capacity for protein synthesis and may be interpreted as a sign of advanced neuronal maturation. Additionally, L-glutamate exposure dramatically increases the number of synaptic profiles. Synapses are structurally more mature: synaptic clefts are distinct; post-synaptic densities are uniformly present; pre- and post-synaptic thickenings occupy a larger area; synaptic vesicles are increased in number ( $70 \%$ increase) and are often closely associated with presynaptic thickenings. The issue of whether these effects are receptor mediated and, if so, by which glutamate receptor subtype, has not been addressed. It will be important to distinguish whether the trophic properties of glutamate are mediated via specific EAA receptors or are the result of effects on intermediary metabolism. Similar structural changes to those discussed above accompany repetitive stimulation of presynaptic pathways in vitro as well as increased patterned afferent input during development in vivo ${ }^{30}$, $143,177,199$. Prolonged exposure to EAA receptor antago- nists during development may potentially retard and/or disrupt these maturational changes produced by glutamate and interfere with normal $\mathrm{CNS}$ development.

\section{REGULATION OF NEURONAL CIRCUITRY AND CY- TOARCHITECTURE}

In addition to their involvement in information coding; many neurotransmitters influence the structure of developing neurons and their pattern of interconnectivity. Acetylcholine, dopamine, GABA, serotonin and somatostatin differentially regulate neuronal outgrowth and growth cone motility in vitro and in vivo ${ }^{118}$. Regulation of neurite growth from neurons is dependent on the level of cytosolic calcium in the growing tip of neurites ${ }^{5,22,37}$. The ability of neurotransmitters to influence neurite growth is likely related to their capacity to alter cytosolic calcium levels. Since the NMDA ionophore is permeable to calcium, regulation of NMDA receptor activation could affect neurite outgrowth. In fact, Pearce et al. ${ }^{178}$ demonstrated that glutamate via an action at NMDA receptors stimulates neurite outgrowth from cerebellar granule cells. Cultures of dissociated granule cells from 4-5-day-old rats normally grow neurites (axonal in nature) after several hours in culture. Application of kynurenate, a non-selective glutamate antagonist (and an antagonist of the glycine modulatory site), to these cultured granule cells for $8 \mathrm{~h}$ reduced the number of cells extending neurites by $54 \%$. The inhibitory effects of kynurenate were prevented in a dose-related manner by addition of exogenous glutamate suggesting that the effect of kynurenate was mediated at glutamate receptors. It appears that the concentration of endogenously released glutamate is sufficient to promote neurite outgrowth, since enzymatic removal of glutamate from the culture medium resulted in a $50 \%$ reduction in the number of granule cells extending neurites. Furthermore, addition of the selective NMDA receptor antagonist D-APV reproduced the inhibitory effects of kynurenate with a maximal effect at $30 \mu \mathrm{M} \mathrm{D}-\mathrm{APV}$, suggesting that NMDA receptors may mediate these processes. However, NMDA stimulated PI turnover may also contribute to this effect.

The effects of EAAs on neurite outgrowth have been extended by Brewer and Cotman, ${ }^{26 a}$ by demonstrating that both neurite extension and branching are controlled by NMDA receptor activation. Exposure of cultures of isolated dentate granule neurons obtained from PND 4 rats to NMDA $(20 \mu \mathrm{M})$ or glutamate $(25 \mu \mathrm{M})$ for 6 days increased the number of neurite branch points by $230 \%$ and increased the total length of neurites by $240 \%$, but did not alter the mean neurite length per branch compared to similarly treated cultures in the absence of 
EAAs. Exposure to $25 \mathrm{mM} \mathrm{KCl}$ produced similar changes although smaller in magnitude compared with NMDA or glutamate $(170 \%$ increased total neurite outgrowth, $60 \%$ increased branching). The neurotrophic effects of NMDA and glutamate were blocked by co-application of the specific NMDA receptor antagonist MK-801 (75\% decrease in number of branch points, $45 \%$ decrease in total neurite length compared to glutamatetreated cultures). Co-application of MK-801, however, increased the mean length of neurite per branch by $250 \%$ compared to glutamate-treated cultures. Thus depending on the level of NMDA receptor activation, NMDA receptors can differentially affect the pattern and extent of neurite extension and branching. The contribution of non-NMDA receptor activation to these effects was not examined in these studies and remains an important issue to be addressed. Whether the neurites examined in this study are either axonal or dendritic in nature is not clear. This is an important issue, since the specific effects of NMDA and non-NMDA agonists on neurite outgrowth differ depending on whether they are axons or dendrites (see below).

In addition to regulation of axonal neurite outgrowth, EAAs can also modulate dendritic growth in some neurons. Mattson et al. ${ }^{120}$ demonstrated that glutamate, in subtoxic doses, produced a specific and progressive set of changes in dendritic growth in cultured hippocampal pyramidal cells dissociated from 18 day old rat fetuses. Exposure to concentrations of glutamate up to $10 \mu \mathrm{M}$, for $2 \mathrm{~h}$, suppressed the rate of dendrite elongation in 4 day old pyramidal neurons. Higher levels of glutamate produced a dose-dependent regression of dendritic material. The ability of glutamate to regulate dendrite growth began at day 2 in culture and peaked by day 4 . The effects of glutamate could be blocked by the non-selective glutamate antagonist $\gamma$-D-glutamylglycine (DGG), but not by D-APV, a selective NMDA receptor antagonist, and the effects of glutamate were mimicked by quisqualate and kainate but not by NMDA. These data suggest that the level of activation of non-NMDA receptors can regulate dendrite growth at this developmental stage. Pyramidal cells at this stage in vitro are not yet sensitive to NMDA, which may indicate that NMDA receptors are not functionally expressed in vitro at this time point. Replication of these experiments at a later stage of neuronal development when pyramidal cells are sensitive to NMDA, such as in 2-week-old cultures, could help determine whether NMDA receptors participate in these regulatory processes. The effects of glutamate on dendrite growth appear to be mediated by regulation of dendritic growth cones, since iontophoresis of glutamate onto individual growth cones of neurons in culture causes a selective retraction of filopodia and corresponding reduction in dendrite growth while not affecting growth of distant dendrites on the same neuron ${ }^{120}$. Glutamate's regulatory actions on dendrite growth may be mediated by calcium mobilization since blockade of voltagedependent $\mathrm{Ca}^{2+}$ channels with $\mathrm{Co}^{2+}$ prevents glutamatemediated dendritic regression ${ }^{120}$. High extracellular $\mathrm{K}^{+}$, which activates voltage-dependent $\mathrm{Ca}^{2+}$ channels or addition of the $\mathrm{Ca}^{2+}$ ionophore, A23187, mimic the effects of glutamate. Taken together, the results suggest that dendritic morphology in vivo may be regulated by the level of EAA receptor activity. In fact, several in vivo studies support this hypothesis ${ }^{143,177,199}$.

Mattson et al. ${ }^{119}$ have recently extended these findings; they examined the regulatory effects of spontaneously released glutamate from afferent axons on dendrite morphology and synaptic sites of target neurons, using a coculture system consisting of entorhinal explants and dissociated hippocampal pyramidal cells. In culture, entorhinal axons spontaneously release glutamate and innervate pyramidal cells that normally receive glutamatergic input from entorhinal neurons in vivo. They found a reduction in dendritic growth in pyramidal neurons grown on entorhinal axons compared to others grown distant from axons. This effect was apparently mediated by glutamate spontaneously released from entorhinal axons, since addition of DGG, a non-selective glutamate antagonist, increased dendrite growth to levels present in pyramidal cells grown away from entorhinal axons. DGG concurrently reduced the number of synaptic sites. In contrast, NMDA did not influence dendritic outgrowth or numbers of synaptic sites, suggesting that the effects of spontaneously released glutamate from entorhinal axons were mediated via non-NMDA receptors. In this experimental paradigm, both addition of tetrodotoxin (TTX) and reduction of extracellular $\mathrm{Ca}^{2+}$ levels, which block synaptic release of EAAs, mimicked the effects of DGG on dendrite growth and synaptic numbers in pyramidal neurons grown on entorhinal axons. Overall, the results support the hypothesis that EAAs have a major role in the formation and regulation of neuronal circuitry in vivo. The major challenge in future experiments will be the determination of the mechanisms by which glutamate receptor activation alters neuronal growth, differentiation and survival and the mechanisms that govern EAA-mediated changes in neuronal circuitry. Whether the observed changes are the result of direct or indirect effects resulting from EAA receptor activation remains to be established. That is, whether these actions are mediated directly by EAA receptor activation or indirectly by EAA-mediated stimulation (or inhibition) of additional effector molecules. For example, glutamate appears to promote sprouting of Helisoma neurons B5 via an indirect mechanism in vivo ${ }^{26 \mathrm{~b}}$; sprouting is depen- 
dent upon a macromolecule(s) whose release is stimulated by glutamate.

\section{REGULATION OF ACTIVITY-DEPENDENT SYNAPTIC PLASTICITY}

Two unique properties of the NMDA receptor/channel complex provide a mechanism by which learning, encoding of memory and selection of appropriate synaptic connections can occur during development and throughout adult life. The NMDA-associated ion channel conducts calcium and is blocked in a voltage-dependent manner by $\mathrm{Mg}^{2+}$ (for a review, see refs. 8 and 122). Activation of the NMDA channel requires transmitter binding to the NMDA recognition site and coincident membrane depolarization (by other afferent input) to relieve the voltage-dependent $\mathrm{Mg}^{2+}$ blockade. Thus NMDA receptor/channel activation requires temporal and spatial correlation between pre-synaptic and postsynaptic activity. This type of interaction may underlie development and stabilization of neuronal connections. These synaptic mechanisms are particularly important during development for selection and stabilization of appropriate neuronal circuitry. This section summarizes results of two major groups of studies, which suggest that NMDA receptors play an integral role in these processes.

\section{1. $L T P$ - forms of learning and memory}

Long-term potentiation (LTP) of excitatory synaptic transmission is a process by which brief repetitive stimuli result in a long-lasting increase in synaptic strength through the activation of post-synaptic NMDA receptors $^{36,158}$. Several in vitro studies indicate that the ability to induce LTP changes during development ${ }^{13}$, 56,85-87. In stratum pyramidale of the hippocampal CA1 subfield, LTP can first be elicited at postnatal day (PND) 5; it is consistently produced at PND 7 (magnitude approximately $25 \%$ of PND 60 values); maximal levels are attained at PND 15 (75\% greater than PND 60 values) and levels then decline to PND 60 (ref. 87). These developmental alterations in LTP roughly correspond to changes in afferent lamination, dendritic arborization and synaptogenesis in this brain region ${ }^{113,180}$. The rapid rise in the magnitude of LTP beginning at PND 7 and transiently peaking at PND 15 relates closely to the ontogeny of NMDA recognition sites in area CA1 which also initially transiently peaks at approximately PND 15 (see Section 2) ${ }^{134}$. Development of LTP in the dentate gyrus occurs more gradually than in area CA1, which is consistent with ultrastructural studies in the dentate gyrus, indicating that synaptogenesis and spine formation are delayed until well into postnatal life ${ }^{41,47}$. As well, expression of NMDA receptors in dentate gyrus increases gradually from PND 7 to adult values ${ }^{134}$. NMDA receptor activation also plays a role in early postnatal olfactory learning in rats ${ }^{10}$. Pharmacological blockade of NMDA receptors by D-APV before olfactory odor preference training in neonatal rats suppresses both behavioral preference and enhanced olfactory bulb responses to the learned odors. Thus, EAA receptors, particularily NMDA receptors, participate in several forms of learning and memory during development.

\subsection{Experience-dependent synaptic plasticity: visual path- ways}

The second group of studies have examined the role of NMDA-mediated processes in experience-dependent synaptic plasticity during critical periods of visual development. During the critical period of consolidation of the ocular dominance of neurons in the visual system of kittens, restriction of visual experience to one eye results in ocular dominance shifts, which favor the experienced eye $^{90}$. The mechanism underlying this form of cortical plasticity is widely accepted to result from competition between converging afferents from each eye. Coincident activity from afferents is proposed to lead to preferential stabilization of the synaptic connections involved whereas non-coincident synapses are eliminated. Kleinschmidt et al. ${ }^{103}$ demonstrated that chronic infusion of the selective NMDA antagonist APV into the visual cortex of kittens blocks the physiologically determined ocular dominance shift normally associated with monocular deprivation. In kittens that received 1 week of monocular deprivation, $74 \%$ of the cortical neurons in the striate cortex responded preferentially to the experienced eye, whereas in kittens in which $50 \mathrm{mM} \mathrm{APV}$ was infused into the striate cortex over the 1 week of monocular deprivation only $29 \%$ of neurons responded preferentially to the open eye. In addition, APV treatment abolished orientation selectivity of neurons in the visual cortex which had developed prior to APV treatment, suggesting that blockade of NMDA receptors affects not only the acquisition but also the maintenance of neuronal selectivity and responsiveness.

Rauschecker and $\mathrm{Hahn}^{187}$ have demonstrated that administration of ketamine, a non-competitive NMDA receptor antagonist, prevented the consolidation of the ocular dominance shift normally associated with brief monocular experience in dark-reared kittens. In darkreared kittens repeated monocular visual experience for $20 \mathrm{~min}$ every other day (15 times) typically results in a shift in the responsivity of neurons in the visual cortex favoring the experienced eye. Administration of ketamine (intramuscular injection, $25 \mathrm{mg} / \mathrm{kg}$ ) immediately after each period of monocular experience prevented the shift of ocular dominance of neurons in the visual cortex; 
administration of ketamine $1 \mathrm{~h}$ after each experience did not prevent consolidation of ocular dominance shifts. Therefore, the ketamine-sensitive component of ocular plasticity consolidation occurs within $1 \mathrm{~h}$ of the visual experience.

At present, there is considerable controversy regarding the mechanisms by which chronic blockade of NMDA receptors alters visual ocular dominance plasticity in kittens. Are the induced changes the result of blocking events specific to plasticity and/or the result of blocking normal visually evoked activity in the striate cortex? It appears that blocking events that are specific both to plasticity and to normal sensory processing are likely to contribute to these changes. For example, procedures which block normal sensory processing in the visual cortex, such as anesthesia or TTX treatment, prevent the effects of monocular deprivation ${ }^{67 b, 189 a}$. Furthermore, NMDA receptor activation contributes significantly to synaptic transmission occurring during normal sensory processing in kitten and cat visual cortex ${ }^{67 a, 142 a, 233}$. Further studies are necessary to determine the relative contribution of blocking normal sensory processing to the visual ocular dominance changes associated with chronic NMDA receptor blockade and to delineate the additional plasticity specific mechanisms related to these changes.

Although tadpoles (Rana pipiens) normally do not possess ocular dominance columns, surgical implantation of a third eye results in stereotyped ocular dominance columns as the result of segregation of inputs from normal and supernumerary eyes within the same tectum (Fig. 5) ${ }^{189}$. Studies using tetrodotoxin to block action potentials in optic nerve demonstrate that the mechanisms for synaptic rearrangement or fine-tuning require retinal ganglion cell activity ${ }^{189}$. Recently, Cline et al. ${ }^{35}$ have shown that NMDA mediated processes regulate segregation of retinotectal projections in surgically produced 3-eyed tadpoles. Eye-specific columns were labeled by applying horse-radish peroxidase to optic nerves. Chronic exposure of the tectum for 2-4 weeks to the NMDA antagonist D-APV $(10 \mu \mathrm{M})$, but not the inactive L-isomer, desegregated the morphologically defined ocular dominance columns in 3-eyed tadpoles (see Fig. 5). Chronic treatment (10 weeks) with the noncompetitive NMDA antagonist MK-801 $(10 \mu \mathrm{M})$ also resulted in desegregation of eye-specific stripes, but only when NMDA ( $1 \mathrm{mM})$ was also applied ${ }^{35 b}$. The obligatory role of NMDA presumably reflects the use-dependent nature of NMDA channel blockers like MK-801 ${ }^{100,117}$. Furthermore, chronic tectal exposure to NMDA (100 $\mu \mathrm{M})$ for 4 weeks sharpened and straightened the borders of the columns ${ }^{189}$. Lower concentrations of NMDA (1 $\mu \mathrm{M})$ produced no apparent effects while higher concentrations $(10 \mathrm{mM})$ were neurotoxic ${ }^{35 b}$. The affects of
NMDA agonists and antagonists upon gross morphologic segregation of retinotectal inputs into tectal columns appears to reflect ultrastructural changes in the terminal arbors of the retinotectal inputs such that the degree of overlap between converging retinotectal terminal arbors is altered ${ }^{35 a, 35 b}$. These results are consistent with the high density and laminar distribution of EAA receptors in the tadpole tectum and with the role of NMDA receptor/ channels in eye-specific segregation of retinotectal afferents $^{128}$.

NMDA receptors also appear to play a role in the activity-dependent matching of binocular tectal maps in Xenopus frogs ${ }^{200 a}$. The Xenopus tectum receives binocular visual input; a direct contralateral retinotectal projection and an indirect ipsilateral isthmotectal projection. During a critical period of normal development (early postmetamorphesis), isthmotectal connections rearrange within the tectum to regions with corresponding retinotectal receptive fields, thereby forming congruent binocular maps within the tectum ${ }^{234 b}$. The processes by which isthmotectal connections are rearranged to match corresponding retinotectal receptive fields are influenced by visual experience ${ }^{234 a}$. Experimental rotation $\left(90^{\circ}\right)$ of the left eye, during or prior to the critical period for isthmotectal plasticity, results in congruent $90^{\circ}$ rotated visual maps in the right tectum. However, chronic treatment with the NMDA receptor antagonists APV or CPP during this period blocks the matching of the
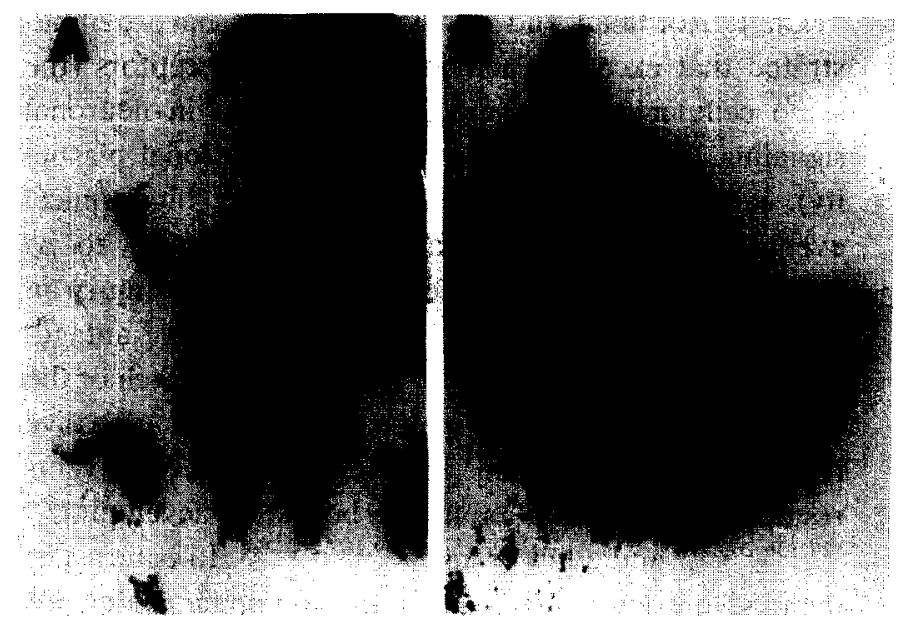

Fig. 5. Effect of the competitive NMDA receptor antagonist DL-APV on segregation of retinal ganglion afferents into eyespecific columns in the tectum of surgically produced 3-eyed tadpoles. A: a tectum from a surgically produced 3-eyed tadpole shows the stereotypical striped pattern representing the segregation of the supernumerary retinal afferents from the afferents of the normal eye. B: a tectum from an animal chronically treated with 10 $\mu \mathrm{M}$ DL-APV for 4 weeks displays complete overlap of supernumerary and normal retinal projections. In $A$ and $B$ supernumerary optic nerves were injected with horseradish peroxidase and fluoresceinconjugated isothiocyanate-Elvax was implanted over the tectum as a sham control (A) and to deliver DL-APV (B). Courtesy of Dr. II.T. Cline. 
ipsilateral (isthmotectal) map to the contralateral (retinotectal) map, ${ }^{200 a}$ while chronic treatment with NMDA allows such matching. Therefore, the data suggest that NMDA receptors play a role in experience-dependent establishment of matching binocular maps during $\mathrm{Xe}$ nopus development. The effects of NMDA antagonists on the segregation of retinotectal connections in 3-eyed tadpoles and on the matching of binocular maps in Xenopus frogs does not appear to be attributable to a reduction in post-synaptic activity resulting simply from attenuation of visual input to the tectum. Chronic application of these antagonists does not reduce visual input to the tectum ${ }^{53 a, 200 a}$. However, blockade of NMDA receptors appears to uncouple communication between coincident visual input and thereby disrupting the processes responsible for stabilizing coactive inputs.

The preceding data indicate that NMDA receptor mediated processes participate in the regulation of a variety of forms of neural and behavioral plasticity during development. The ability of EAAs to produce these changes is often restricted to small time windows during postnatal development and parallels development of preand post-synpatic markers of EAA pathways (see Section 6). The results further imply that EAA neurotransmitters regulate neuronal plasticity in these pathways in vivo during development.

\section{MECHANISMS OF EAA NEUROTOXICITY}

Choi, Rothman and Olney and others have demonstrated that excessive activation of EAA receptors (the same cellular mechanisms that participate in neuronal signaling, neurotrophic influences and neuronal plasticity) can initiate a series of intracellular biochemical events that cause neuronal damage (referred to as 'excitotoxicity') $)^{32,166,195}$. Excitotoxic neuronal injury in the immature brain can be blocked by selective antagonists of EAA receptors ${ }^{125,129,131,132,135,136,234}$. Each of the EAA receptor subtypes, under conditions of excessive receptor activation, may initiate a cascade of events resulting in neuronal injury in both the developing ${ }^{39}$. $127,136,209,220$ and adult brain ${ }^{66,149,167,203,222}$. In contrast to the in vivo excitotoxic effects of the glutamate analogues, NMDA, quisqualate and kainate (which are not appreciably taken up by the high-affinity glutamate uptake system), glutamate mediated toxicity in vivo is usually only manifested when the presynaptic uptake system is overloaded or suppressed (i.e. under conditions of metabolic stress) ${ }^{104,123,159}$.

The mechanisms underlying EAA neurotoxicity can be divided into two distinct component processes based largely on in vitro studies (see Fig. 6) ) $^{32,195}$. The first involves depolarization of neuronal membranes, $\mathrm{Na}^{+}$ influx followed by secondary passive $\mathrm{Cl}^{-}$and $\mathrm{H}_{2} \mathrm{O}$ influx, and subsequent neuronal swelling. The second phase is characterized by excessive calcium influx, primarily via NMDA receptor/channel activation, activation of second messenger systems, mobilization of internal $\mathrm{Ca}^{2+}$ stores, activation of lipases and proteases, generation of fatty acids and free radicals, mitochondrial dysfunction and depletion of energy stores (for a review, see refs. 32 and 195). These cellular derangements lead to destruction of neuronal cytoskeletal and membrane components and ultimately neuronal death. In fact this scenario appears to be a central pathway leading to neuronal injury resulting from a wide variety of CNS insults (see Fig. 7). Under conditions of metabolic stress or depleted cellular energy, high-affinity uptake of EAAs is compromised, because this process is highly energy dependent. In fact, intracerebral injections of NMDA acutely ( $1 \mathrm{~h}$ postinjection) and transiently disrupt high-affinity synaptosomal $\left[{ }^{3} \mathrm{H}\right]-$ glutamate uptake (McDonald, J.W., Johnston, M.V. and Silverstein, F.S., unpublished observations). The result-

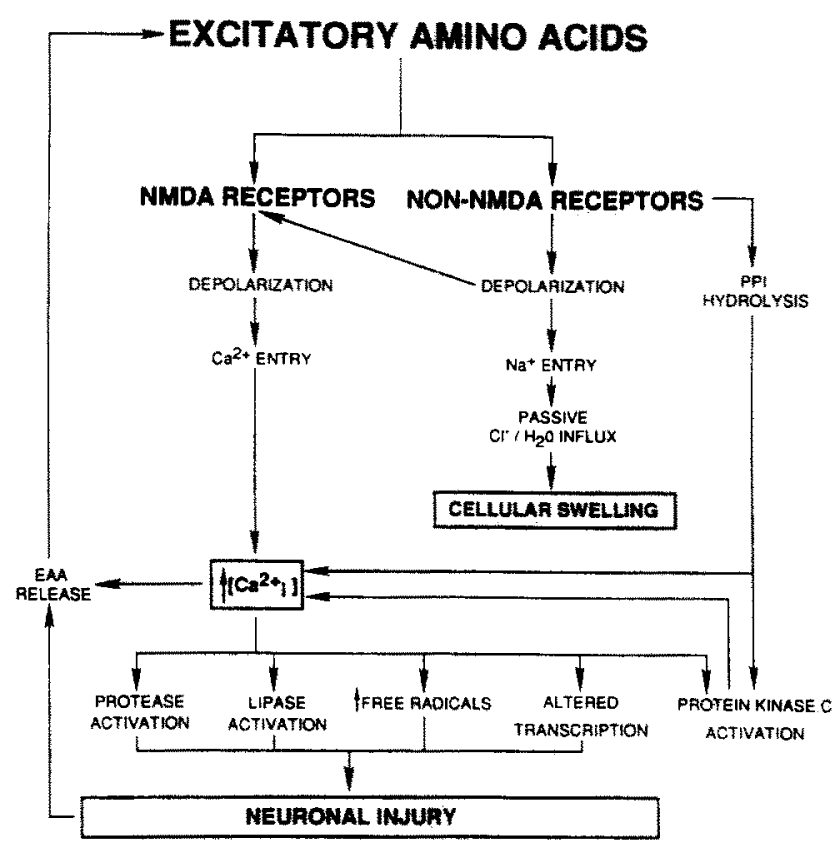

Fig. 6. This schematic diagram summarizes some of the mechanisms that may contribute to EAA neurotoxicity. In vitro experiments suggest that EAA neurotoxicity may have two components. The first component, mediated by excessive activation of non-NMDA receptors, is characterized by influx of $\mathrm{Na}^{+}$followed by passive influx of $\mathrm{Cr}^{-}$and $\mathrm{H}_{2} \mathrm{O}$ which may produce osmotic neuronal swelling. These are acute events occurring within hours of exposure to EAA agonists. The second, more prominent component is produced by overactivation of NMDA receptors which leads to a rise in the intracellular concentration of $\mathrm{Ca}^{2+}$. A sustained rise in intracellular $\mathrm{Ca}^{2+}$ may trigger a biochemical cascade of events that lead to neuronal injury and death. Furthermore, activation of a subset of non-NMDA receptors coupled to polyphosphoinositide hydrolysis may also elevate intracellular $\mathrm{Ca}^{2+}$. EAAs released from synaptic terminals would further propagate neuronal injury. Adapted from Choi, $1988^{32}$. 
ing accumulation of EAAs in the synaptic cleft will prolong activation of EAA receptors, produce sustained membrane depolarization and lead to large ionic fluxes. Since energy is required to extrude $\mathrm{Ca}^{2+}$ from the cell and maintain ionic balances across neuronal membranes, excessive neuronal activation will exacerbate any imbalance between cellular energy requirements and energy availability. These recurrent mechanism resulting in metabolic stress and energy depletion may ultimately produce excitotoxicity ${ }^{159}$. Multiple physiologic factors that exacerbate energy depletion may contribute to EAA mediated neurotoxicity.

Thus excitotoxicity is manifested under conditions of excessive and sustained post-synaptic EAA-receptor activation which gives rise to a critically sustained intracellular level of $\mathrm{Ca}^{2+}$ and leads to uncontrolled neuronal autolysis. The relative contribution of pre- and postsynaptic neuronal mechanisms and glial mechanisms to excitotoxicity is difficult to ascertain, although all these mechanisms are likely contribute. Both presynaptic neuronal and glial events can produce sustained EAA receptor activation via an increase in the synaptic concentration of EAAs if high-affinity uptake systems for EAAs are compromised. Furthermore, enhanced presynaptic release will increase the synaptic concentration of EAAs. However, changes in the state of energy metabolism in the post-synaptic cell will determine the balance between normal EAA function and excitotoxicity. For example, intracellular homeostatic events will normally prevent excitotoxicity from occurring during normal synaptic activity. However, these homeostatic mechanisms may become compromised during states of altered energy metabolism and excitotoxicity may be mainfested.

Overactivation of EAA receptors, particularly NMDA receptor subtypes, has been implicated in the pathogenesis of neuronal injury in a number of acute neurologic disorders (see Fig. 7) including hypoxia-ischemia, ${ }^{4,124,}$ $193,194,212,213$ hypoglycemia ${ }^{243}$, sustained seizures ${ }^{38,107,149}$, physical brain trauma ${ }^{60}$ and chronic neurodegenerative diseases including Huntington's disease ${ }^{14,46,137,245}$, Alzheimers disease $\mathrm{e}^{116}$, lathyrism ${ }^{218}$, and amyotrophic lateral sclerosis $^{219}$ (for reviews see refs. 58,78,140,192 and 195). Several groups have demonstrated that selective antagonists of the NMDA receptor channel reduce the severity of brain injury resulting from focal hypoxia-ischemia when administered before or several hours after the insult (see subsection 9.1). NMDA receptor antagonists may provide a novel clinical therapy in these acute and chronic neurologic disorders (see Sections 9 and 10). The relative role of non-NMDA-type EAA receptor mediated excitotoxity in these neurologic disorders will be able to be determined with the advent of specific and potent non-NMDA receptor antagonists.

\section{DEVELOPMENTAL ALTERATIONS IN EAA NEUROTOX-} ICITY

One of the strongest lines of evidence for developmental regulation of EAA synapses comes from developmental neurotoxicity studies. The rank order of neurotoxic potency for the selective EAA agonists, NMDA, quisqualate and kainate is markedly different in the developing and mature brain (Table III; Fig. 8). The sensitivity of neurons to EAA neurotoxicity changes markedly during development. Different brain regions and different neuronal types exhibit their own developmental profile of susceptibility to each of the selective EAA receptor agonists.

Although kainate is a potent neurotoxin in the adult brain, kainate is relatively non-toxic in the immature brain (Fig. 8$)^{45}$. However, paradoxically, kainate does produce prolonged tonic clonic seizures in immature animals. The susceptibility of rodent striatal neurons to kainate neurotoxicity initially appears at PND 7 and gradually rises to adult levels by PND $21^{28}$. The maturational sensitivity to kainate neurotoxicity parallels the development of glutamatergic innervation to the striatum as measured by synaptosomal uptake of $\left[{ }^{3} \mathrm{H}\right]$ glutamate and by high-affinity $\left[{ }^{3} \mathrm{H}\right]$ kainate receptor binding. Similar developmental trends to kainate toxicity have been reported in the hippocampus ${ }^{244}$. Also, the susceptibility of Purkinje, Golgi and granule cells to kainate neurotoxicity in rat cerebellar slices increases during early postnatal development ${ }^{70}$.

There is a unique ontogenic profile of susceptibility to NMDA-mediated brain injury which varies between brain regions and these changes may be associated with physiological changes in NMDA receptor regulation. In contrast to the response to kainate, the susceptibility of the developing brain to NMDA toxicity in vivo transiently peaks near PND 7 in rats (Fig. 9) (ref. 127). The severity of brain injury produced by direct intrastriatal infusion of equimolar NMDA is approximately 60 times greater at PND 7 compared to adults (assessed by measurement of regional cross-sectional areas). The severity of NMDA-mediated brain injury at PND 1, 14, 21 and 28 is comparable to that produced by NMDA in adults whereas intermediate levels of brain injury are present at PND 4 and PND 10 and peak levels are present at PND 7. A similar profile is observed in the hippocampus. Also, NMDA toxicity appears to peak at different developmental time points in various brain regions ${ }^{173}$. Furthermore, the developmental susceptibility to NMDA toxicity differs markedly between different neuronal populations within a given brain region. In rat cerebellar slices the developmental profile of vulnerability to NMDA toxicity differs markedly between neuronal 


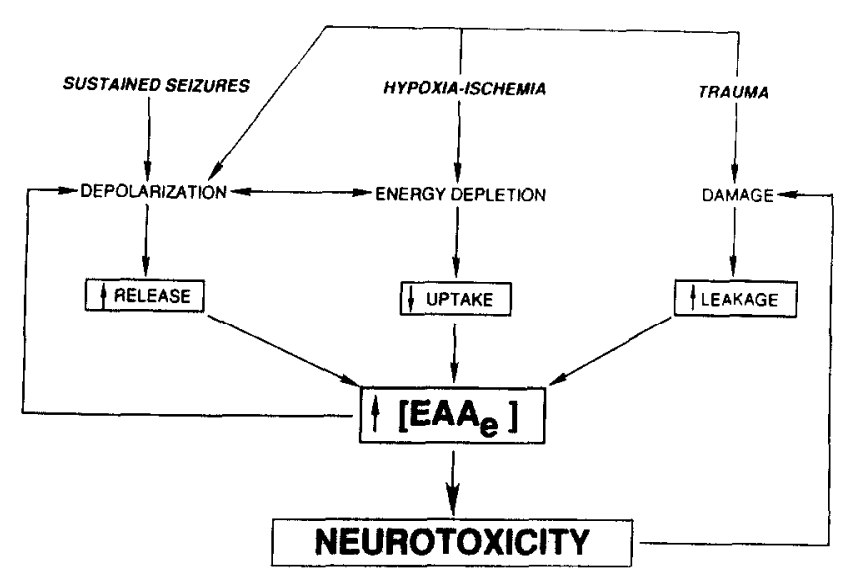

Fig. 7. This diagram illustrates the possible role of EAA neurotoxicity in acute brain injury. EAA neurotoxicity may be a common mechanism in neuronal injury resulting from sustained seizures, hypoxia-ischemia and physical brain trauma. All these conditions tend to elevate the extracellular concentration of EAAs via different mechanisms. As detailed in Fig. 6, excessive activation of EAA receptors, due to elevated concentrations of EAAs in the synaptic cleft, can result in neuronal injury and death. There are two recurrent pathways that could make these mechanisms self-propagating. Adapted from Choi, $1988^{32}$.

types; Purkinje cells remain insensitive, Golgi cells become more sensitive and granule cells become less sensitive with postnatal development ${ }^{70}$.

Since NMDA mediated excitotoxicity is believed to play a major role in the pathology of hypoxic-ischemic brain injury, it may be predicted that the developmental profiles of susceptibility to NMDA- and hypoxic-ischemic brain injury should be parallel. In fact, Ikonomidou et al. ${ }^{92}$ have recently validated this hypothesis by demonstrating that the developmental susceptibility to hypobaric-ischemic brain injury has a similar profile to NMDA toxicity in vivo in rodents.

The ontogenic profile of NMDA toxicity does not appear to be related to any one identifiable change in the expression or regulation of NMDA receptors but rather is likely to be the result of several independent but not mutually exclusive mechanisms including developmental changes in: the expression of NMDA receptors, the regulation of NMDA receptor activation, the functional expression of synaptic inhibition and the regulation of events occurring after NMDA receptor activation (generation and subcellular localization of second messengers, phospholipases, proteases, phosphorylases and phosphatases, etc. and other events that regulate intracellular calcium buffering). The peak sensitivity to NMDA toxicity does not correlate precisely with the ontogeny of NMDA-sensitive $\left[{ }^{3} \mathrm{H}\right]$ glutamate binding sites or the relative expression of the associated NMDA modulatory binding sites which lag behind susceptibility to NMDA toxicity. However, the transient expression of NMDA toxicity is consistent with several additional physiological

\section{TABLE III}

Relative neurotoxicity of specific EAA-receptor agonists in PND 7 and adult rats

The relative neurotoxicity produced by intracerebral injections of the specific EAA-receptor agonists NMDA, quisqualate and kainate is markedly different in the adult and immature brain. On an equimolar basis, in the immature brain NMDA produces the greatest degree of brain injury in comparison to quisqualate and kainate. In contrast, kainate is the most toxic in the adult brain followed by NMDA. These comparisons are derived from literature data ${ }^{39,127,136,149,167}$, $209,220,222$.

\begin{tabular}{ll}
\hline PND 7 & $\begin{array}{l}\text { NMDA }>>>\text { quisqualate }>\text { kainate }=0 \\
\text { kainate }>>\text { NMDA } \geqslant \text { quisqualate }\end{array}$ \\
\hline
\end{tabular}

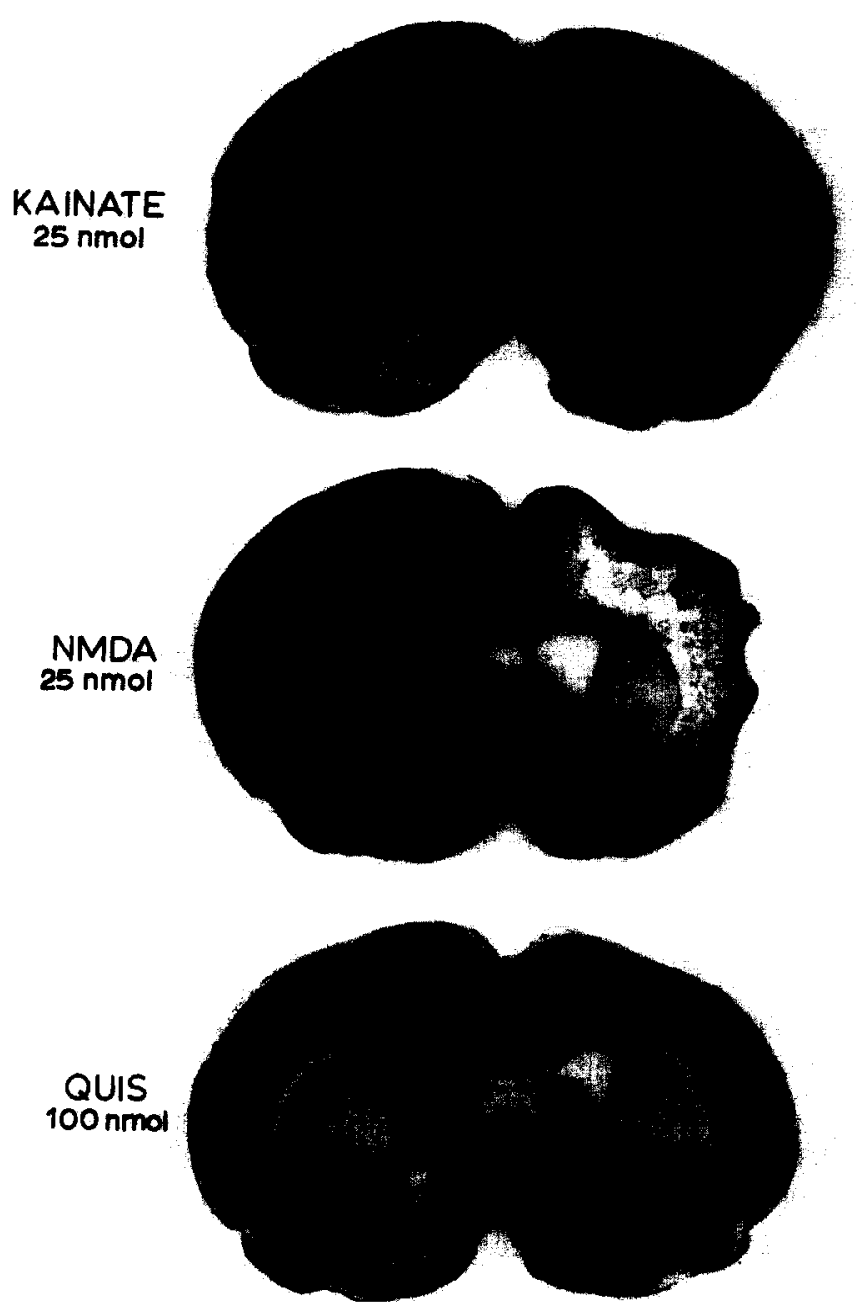

Fig. 8. Comparison of the severity of excitotoxic brain injury produced by the selective EAA receptor agonists NMDA, quisqualate and kainate. PND 7 rats received unilateral intrastriatal injections (right hemisphere) of either NMDA $(25 \mathrm{nmol} / 0.5 \mu \mathrm{l})$, quisqualate $(100 \mathrm{nmol} / 0.5 \mu \mathrm{l})$ or kainate $(25 \mathrm{nmol} / 0.5 \mu \mathrm{l})$. Animals were sacrificed on PND 12. All 3 agonists produced prolonged tonic-clonic seizures. Injections of NMDA produced the greatest degree of brain injury whereas quisqualate injections produced less brain damage. In contrast, kainate injections produced few signs of neuronal injury. 
measurements of NMDA receptor function in development.

During development there are specific laminar changes in the sensitivity of hippocampal area CA1 to NMDA as measured by decreases in extracellular $\mathrm{Ca}^{2+}$ and concomitant field potentials; responses to NMDA transiently peak in stratum pyramidale between PND 5-9 (ref. 83). Furthermore, recent experiments suggest that NMDA receptors in the visual cortex are more effective during development than in adulthood ${ }^{67 a, 233}$. Also, NMDAdependent spontaneous EPSPs and recurrent synchronized burst activity are present in hippocampal area CA3 only during the first few weeks of postnatal life in rats $^{17,25,101}$. The biophysical properties of the NMDA receptor/channel complex also change during development and these changes may contribute to the observed developmental changes in NMDA toxicity. In hippocampal slices, the voltage-dependent magnesium blockade of the NMDA associated ionophore is less consistent at PND 8 compared to adults ${ }^{16}$. Furthermore, the ionic dependency of this voltage dependent blockade changes during development such that lowering the extracellular concentration of $\mathrm{Ca}^{2+}$ from $2 \mathrm{mM}$ to $1 \mathrm{mM}$ selectively reduces the voltage dependency of NMDA responses in immature rats (PND 9-16) compared to adults ${ }^{26}$. These changes in the voltage dependency of NMDA responses would be predicted make the developing brain more susceptible to NMDA mediated brain injury.

In contrast to NMDA, quinolinate (an NMDA receptor agonist) is a potent neurotoxin in the adult brain but relatively weak in the immature brain although it elicits seizures in both adult and immature brain ${ }^{66,136,203}$. This observation suggests the presence of subtypes of NMDA receptors. Quinolinate may act as a subset of NMDA receptors that increase in number during development. Differential developmental changes in the metabolism and pharmacokinetics of these excitotoxins may also contribute to these effects.

Susceptibility of striatal and hippocampal neurons to quisqualate-mediated brain injury during postnatal development does not change as markedly as NMDA toxicity although toxicity appears to transiently peak in younger animals between PND 7-14 ${ }^{88,136,209}$. The vulnerability of Purkinje and Golgi cells increases with postnatal age in rat cerebellar slices while granule cells remain unaffected throughout development ${ }^{70}$. The susceptibility to toxicity produced by the ionotropic nonNMDA receptor agonist, AMPA, also transiently peaks between PND 7-14 with peak values at PND 10. However, AMPA is $10-15$ times more potent (on an

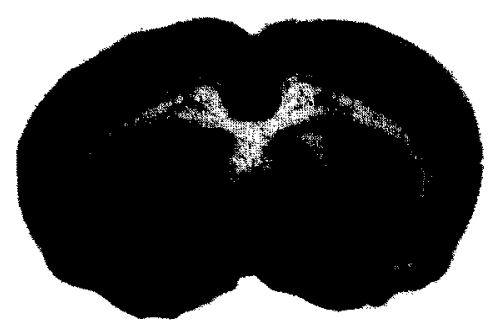

PND 1

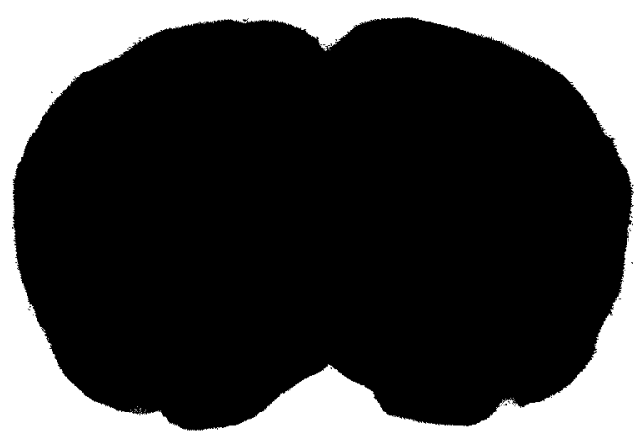

PND 14

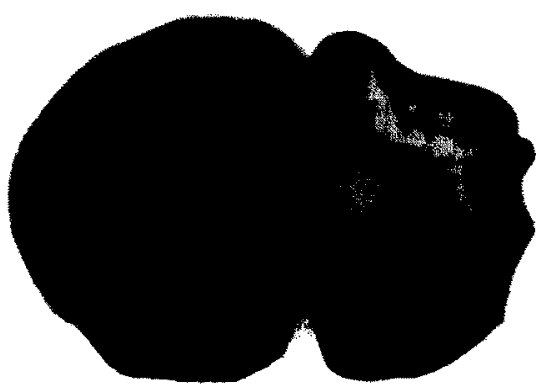

PND 7

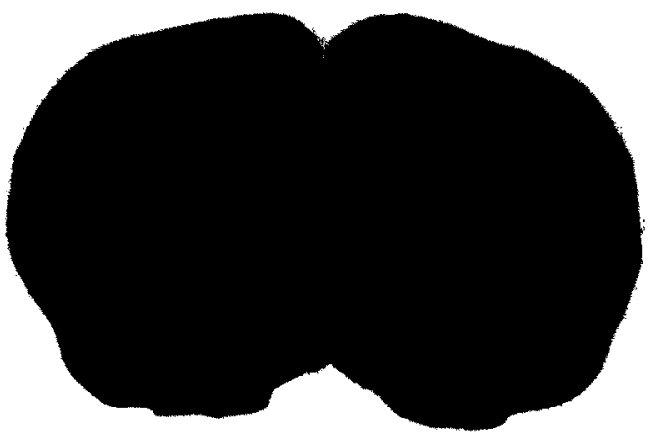

PND 21

Fig. 9. Ontogeny of NMDA-mediated brain injury. Comparison of Nissl-stained coronal brain sections at the level of the corpus striatum from PND $1,7,14$ and PND 21 rats that received unilateral intrastriatal injections of $25 \mathrm{nmol}(0.5 \mu 1$ injection volume $)$ NMDA. Animals were sacrificed 5 days later. The severity of brain injury is maximal at PND 7; the lesion is characterized by confluent neuronal necrosis involving the striatum and extending into the thalamus, dorsal hippocampus and overlying neocortex. In comparison to PND 7, the severity of NMDA-mediated brain injury is substantially reduced at PND 1, 14 and PND 21 . 
TABLE IV

Dissociation of EAA-mediated seizures and excitotoxicity in $P N D 7$ rats

1 Unilateral intracerebral injections of NMDA or quisqualate produce bihemispheric synchronous seizure activity and only ipsilateral brain injury.

2 Kainate is a potent convulsant but a weak neurotoxin in PND 7 rats.

3 Pharmacological blockade of seizure activity does not consistently reduce NMDA-mediated brain injury.

equimolar bases) than quisqualate as a neurotoxin when injected intracerebrally in PND 7 rats (McDonald, J.W. et al., unpublished observations). The difference in potency may reflect fundamental differences between ionotropic and metabotropic-type quisqualate receptors and/or differences in neuronal uptake or metabolism of these agonists in vivo.

The neurotoxic potential of EAAs is not limited to postnatal development. Glutamate produces neurotoxicity in fetal brain when administered to pregnant mice and monkeys, which indicates that EAAs can penetrate the placental barrier and suggests that EAA receptors are functionally expressed early in development ${ }^{148,167,230}$. These results are consistent with the presence of EAA receptors in human fetal brain (see Section 3).

The differential ontogeny of specific EAA agonistmediated neurotoxicity may relate to reported agedependent differences in the potency of EAA receptor antagonists against EAA-mediated neurotoxicity. For instance, the non-competitive NMDA antagonist MK801 is approximately 10 -fold more potent as a neuroprotectant against NMDA- and hypoxia-ischemia-mediated neuronal injury in immature rodents than in adults ${ }^{67}$. $76,124,131$. Also, virtually complete neuroprotection can be achieved with NMDA antagonists in immature brain in contrast to only partial protection in adults. These results are consistent with the enhanced effectiveness of NMDA antagonists in the kitten cortex relative to adults ${ }^{67 \mathrm{a}}$, $142 a, 2.33$ Based on the relative potencies of the specific EAA agonists in adult and immature brain, glutamate toxicity would be mediated predominately by NMDA and quisqualate/AMPA receptors in the immature brain and by kainate in the adult brain. This hypothesis can also account for the relative lack of neuroprotective effects of NMDA antagonists against hypoxia-ischemia in adult brain in certain models ${ }^{20}$. In adults combinations of NMDA and non-NMDA antagonists will probably be required to achieve maximal levels of protection.

Several lines of evidence indicate a dissociation between EAA-mediated seizures and brain damage in the immature brain (Table IV). Unilateral intrastriatal injections of NMDA or quisqualate produce bihemispheric synchronous high-voltage and high-frequency epileptiform discharges; however, the damage is confined to the injected hemisphere ${ }^{131}$. Coupled with the ability of kainate and quinolinate to elicit seizures in the absence of neuronal injury in PND 7 rats $^{66,136,244}$ these results suggest that prolonged seizure activity is not always sufficient to produce neuronal injury. Furthermore, seizure activity is not necessary to produce NMDA mediated brain injury, since anticonvulsants such as phenytoin, diazepam and pentobarbital do not block NMDA-induced injury in PND 7 rats although they prevent seizure activity ${ }^{125,136}$.

In summary, agonists specific for each EAA receptor subtype possess a unique developmental neurotoxicity profile. The relative ability of these agonists to produce brain injury in PND 7 rats compared to adult rats is: kainate $>>N M D A \geq$ quisqualate in adults vs NMDA $>>>$ quisqualate $>$ kainate $=0$ in PND 7 rats. Furthermore, the developmental susceptibility of different brain regions and specific neuronal populations to EAA neurotoxicity differs markedly. Taken together the results suggest that the developing brain is extremely susceptible to neurotoxicity during restricted developmental periods and that NMDA and quisqualate/AMPA antagonists may provide more effective therapy against excitotoxic neuronal injury in immature brain. During development, selective neuronal vulnerability to excitotoxic injury will be a function of the relative contribution of each EAA receptor subtype to excitotoxicity and their regional pattern of development. Depending on the stage of development and degree of excitation of EAA neurotransmitter pathways, EAAs can exert neurotrophic as well as neurodegenerative influences.

\section{ROLE OF EAAS IN DEVELOPMENTAL NEUROLOGIC DISORDERS}

Several lines of research suggest that endogenous EAAs contribute to the pathophysiology of neuronal injury in some of the major neurologic disorders that affect the developing brain (Table $V$ ). The strongest experimental support is for a role of EAAs in hypoxiaischemia and prolonged seizures. Also, EAAs may have a specific role in the pathogenesis of selective neuronal injury resulting from two rare developmental disorders of amino acid metabolism: non-ketotic hyperglycinemia and sulfite oxidase deficiency. Furthermore, a growing body of evidence suggests that EAAs may regulate neuroendocrine homeostasis and that aberrations in this regulation may lead to developmental neuroendocrine disorders. Ontogenic changes in the regulation and expression of EAA receptors may relate to the developmental onset and susceptibility to particular neurologic disorders. 
TABLE V

Acute developmental neurologic disorders in which excitotoxic mechanisms may contribute to neuronal injury

1 Hypoxia-ischemia (e.g. near drowning, cerebral palsy)

2 Sustained seizures (e.g. status epilepticus, febrile seizures)

3 Physical brain trauma

4 Disorders of amino acid metabolism

(a) non-ketotic hyperglycinemia

(b) sulfite oxidase deficiency

5 Endocrinopathies (e.g. stunted skeletal growth, sexual organ hypoplasia, reproductive dysfunction)

\subsection{Hypoxia-ischemia}

Studies in both developing and mature animals suggest that EAAs contribute to the pathogenesis of hypoxicischemic brain injury. EAA agonists are neurotoxic in the developing brain (see Section 8). The topography of hypoxic-ischemic brain injury roughly corresponds to the distribution of EAA receptors in brain ${ }^{124,210,211}$. Furthermore, hypoxia-ischemia produces sustained neuronal depolarization and large increases in synaptic glutamate release and/or concomitant inhibition of high-affinity glutamate uptake, resulting in a rise in the extracellular concentration of EAAs which may produce excitotoxicity ${ }^{18,55,84,208}$. Hypoxic-ischemic brain injury is dependent upon EAA afferent input; selective ablation of putative glutamatergic afferents limits the extent of hypoxic-ischemic neuronal injury ${ }^{94,97,176,242}$. Finally, hypoxic-ischemic neuronal injury is reduced when animals are either pre-treated or post-treated with EAA antagonists, particularly NMDA receptor antagonists, ${ }^{4,124,126,}$ 213. Despite the ability of NMDA receptor antagonists to block the majority of hypoxic-ischemic neuronal injury in developing brain, the distribution of EAA receptors alone cannot explain the pattern of selective neuronal injury. For example, neurons in both hippocampal areas CA1 and CA3 are susceptible to hypoxic-ischemic injury in the neonatal brain whereas neurons in area $\mathrm{CA} 3$ of the adult brain are relatively resistant to injury compared to area CA1 neurons even though both areas have a high density of EAA receptors. Additional neuronal group specific properties such as their relative resistance to hypoxia and energy depletion, their ability to buffer rises in intracellular $\mathrm{Ca}^{2+}$, the subcellular localization of enzymes involved in the excitotoxic cascade and their local external environment may confer selective vulnerability.

\subsection{Sustained seizures}

Similarly, there is evidence suggesting a role of EAAs in the pathogenesis of neuronal injury resulting from status epilepticus and chronic epilepsy. Two major experimental approaches have been applied to the investigation of the role of EAAs in these disorders: analysis of EAA-induced seizures in experimental animals and biochemical assays of surgically excised epileptogenic brain tissue. EAAs are potent convulsants and local injection of EAA-receptor agonists as well as stimulation of EAA-afferent pathways produce a pattern of acute and chronic morphological changes in brain that are similar to the changes found in patients with epilepsy ${ }^{140,149,164,170,200,215}$. EAA-receptor antagonists possess anticonvulsant properties and prevent the morphological changes associated with seizures ${ }^{34 a, 38,48,53}$, 107,140. Furthermore, EAA receptors may participate in the formation of epileptogenic foci in brain, since antagonists of EAA receptors suppress the development of spontaneous seizures and associated neurochemical changes normally produced by kindling - a model of epilepsy ${ }^{24,49,75,139,221}$.

Furthermore, EAAs are elevated in epileptic foci in humans ${ }^{205}$. Recent evidence indicates that there are also increases in NMDA receptor binding in epileptic tissue resected from patients with epilepsy ${ }^{133}$. An epileptogenic focus (e.g. in temporal lobe epilepsy) may arise gradually in an abnormal brain region; underlying neuropathology may be congenital or postnatally acquired. Epileptogenesis may be initiated early in life and may be an ongoing and cycling process of neuronal injury and adaptive synaptic reorganization. An interesting clinical observation is that in medically intractable temporal lobe epilepsy there is fairly often a history of a single prolonged (more than $30 \mathrm{~min}$ ) febrile convulsion in infancy. Neuronal epileptogenic mechanisms may be very active during early brain development, coinciding with developmental periods of maximal sensitivity to NMDA toxicity and enhanced synaptic plasticity. Therapeutic intervention with NMDA receptor antagonists early in this process could conceivably preclude the subsequent formation of an epileptogenic focus. The majority of studies examining the processes that contribute to the development of an epileptogenic focus have relied predominantly on adult animal models. Additional studies that examine these mechanisms in the immature brain are crucial, since it is widely held that epileptogenic processes are initiated early in development in focal epilepsies such as temporal lobe epilepsy.

\subsection{Disorders of amino acid metabolism}

Additional evidence suggests that EAA metabolites may participate in the pathogenesis of acute neuronal damage in two disorders of amino acid metabolism, non-ketotic hyperglycinemia and sulfite oxidase deficiency. In both disorders elevated levels of EAA metabolites are suggested to mediate excitotoxic brain injury. 
9.3.1. Non-ketotic hyperglycinemia. Non-ketotic hyperglycinemia (NKH) is an inherited disorder of glycine metabolism characterized by abnormally high concentrations of glycine in plasma and cerebrospinal fluid in the absence of excess organic acids ${ }^{74}$. It presents in the newborn as myoclonic seizures, hypotonia and respiratory distress and is a well-recognized metabolic cause of overwhelming illness in the first year of life ${ }^{29}$. The associated mortality rate is high and survivors are usually mentally retarded and have intractable seizures. Until recently, the relationship between impaired catabolism of glycine and the pathophysiology of NKH has been unclear. However, several recent observations have provided a greater understanding of the relationship of glycine to excitotoxicity. Glycine enhances NMDAmediated responses at a site closely associated with NMDA receptors ${ }^{95}$. There has been considerable controversy whether the concentration of glycine in brain extracellular fluid is sufficient to maximally potentiate NMDA responses. However, the concentrations of glycine in the synaptic cleft may be maintained relatively low (through an active uptake or removal process) compared to CSF levels. Exogenous glycine can potentiate NMDAmediated synaptic potentials in intact brain tissue in vitro where the endogenous extracellular concentration of glycine is presumably equivalent to the levels present in vivo $^{229}$. Glycine also enhances chemically induced convulsions in vivo when administered intrathecally and this effect is blocked by antagonists of NMDA receptors ${ }^{108}$.

Thus the 3-10-fold elevation of the concentration of glycine in CSF of patients with NKH is likely sufficient to overload any active synaptic glycine uptake or removal process resulting in elevated synaptic concentrations of glycine and potentiation of NMDA responses, which may result in seizures, intracellular calcium accumulation and neuronal injury. Furthermore, the developing nervous system has heightened susceptibility to NMDA-mediated brain injury relative to adults and high levels of glycine may be particularly devastating to the nervous system of the affected neonate (see Section 8). The evidence suggests that the elevated CSF concentrations of glycine in NKH may contribute to the pathophysiology of this disease by overactivating NMDA receptors via an action at the associated glycine modulatory site ${ }^{136 a}$. However, additional experimental evidence is needed to verify this hypothesis.

9.3.2. Sulfite oxidase deficiency. The second identified metabolic amino acid disorder, sulfite oxidase deficiency, is a fatal childhood disorder characterized by widespread neuronal injury and destruction, mental retardation and elevated blood and CSF levels of the EAA L-sulfocysteine ${ }^{93}$. L-Sulfo-cysteine is not normally present in the human body and this abnormal metabolite is the result of a deficiency of the enzyme sulfite oxidase in brain and peripheral organs ${ }^{147}$. Elevated concentrations of this metabolite may become neurotoxic because L-sulfocysteine is not actively taken up by high-affinity glutamate uptake systems ${ }^{11}$. Furthermore, L-sulfo-cysteine produces neuronal injury in retina and hypothalamus when administered peripherally and is also neurotoxic when directly injected into the brain of neonatal rats ${ }^{168}$. The neuropathology produced by L-sulfo-cysteine resembles that produced by other EAA analogues. The above evidence indicates that L-sulfo-cysteine may participate in the pathophysiology of neuronal injury in sulfite oxidase deficiency and suggests that the resulting neuronal injury occurs, in part, via an excitotoxic mechanism.

These disorders may provide useful clinical models in which to explore the neuropharmacology of EAA antagonists and which to discuss the role of EAAs in the pathogenesis of neuronal damage in infancy. These insights also provide a basis for identification of other metabolic disorders in which EAA metabolite-mediated excitiotoxicity may occur.

\subsection{Endocrinopathies}

Disturbances in EAA neurotransmission may also contribute to developmental disorders of neuroendocrine regulation. EAA neurotransmitters may normally participate in the regulation of neuroendocrine homeostasis via actions upon neuronal circuits within the arcuate nucleus of the hypothalamus. Olney ${ }^{162}$ discovered that parenteral administration of monosodium glutamate to neonatal mice produced a lesion of the arcuate nucleus of the hypothalamus that was associated with multiple endocrinopathies including development of obesity, stunted skeletal growth, anterior pituitary and sexual organ hypoplasia and sterility. Additional studies confirmed and extended these findings to include significant alterations in the levels of several gonadotropin hormones, abnormalities in the pulsatile secretion of growth hormone, precocious puberty, disturbed estrous cycles and severe reproductive dysfunction in adult animals ${ }^{154,171}$. Further studies indicated that parenteral administration of subtoxic doses of glutamate and related EAAs to adolescent and adult animals produced marked, reversible alterations in adenohypophysial hormone secretion via an action on a select population of hypothalamic neurons $^{34,169,175,184,198,227}$. Activation of hypothalamic NMDA receptors may underlie the onset of puberty in rodents and primates ${ }^{6,72,73,236}$. These observations suggest that disruption of endogenous EAA neurotransmission, by disease or drugs, at critical periods in development could have long-lasting effects on neuroendocrine function and may have potential to produce a variety of developmental endocrinopathies. 
In conclusion, EAAs may play an important role in a variety of developmental brain disorders including hypoxia-ischemia, epilepsy, as well as metabolic and neuroendocrine disorders. It is likely that excitotoxicity also contributes to physical brain trauma during development as it does in adult rodents ${ }^{60}$. However, additional experimental support in the immature brain will be necessary to verify this hypothesis. The propensity of these disorders to produce neuronal injury would he expected to change dramatically during development based on the dynamic ontogenic changes in susceptibility to selective EAA-agonist-induced neurotoxicity. These results are likely applicable to human infants since prenatal or perinatal exposure (either orally or parentally) to endogenous or exogenous EAA analogues have the potential to destroy neurons and markedly alter normal CNS development in a variety of species ${ }^{27}$, $59,163,165,206,209,217$. Further investigation of the ontogeny of EAA pathways and the developmental regulation of EAA neurotoxicity will aid in the understanding of the pathophysiology of and the susceptibility to several developmental neurologic disorders and in the potential treatment of these conditions.

\section{THERAPEUTIC POTENTIAL OF EAA-RECEPTOR AN- TAGONISTS}

The above evidence, implicating EAAs in neurotoxicity in several developmental brain disorders, coupled with studies that demonstrate that EAA-receptor antagonists are effective in reducing neuronal injury in experimental models of these disorders, provides impetus for the use of EAA receptor antagonists as potential therapy in humans. Since no effective, selective lipophilic antagonists of non-NMDA receptors have been developed, it is difficult to determine the therapeutic potential of non-NMDA receptor antagonists against neuronal injury. However, there are clearly potential beneficial effects of NMDA receptor antagonists in these conditions. In this section, the benefits and potential side effects of EAA receptor antagonists as therapy in developmental disorders will be discussed.

\subsection{Acute therapy}

Several possible side effects of NMDA receptor antagonists may limit their usefulness as neuroprotective agents especially during development. The non-competitive PCP-like NMDA receptor antagonists may be associated with acute schizophrenia-like symptoms similar to those produced by phencyclidine. Depression of synaptic transmission by NMDA receptor antagonists could impair respiratory and cardiovascular control although these functions could be supported artificially.
Furthermore, these antagonists may also transiently interfere with critical stages of synaptic development (see Sections 5 and 6). It is conceivable, however, that the beneficial neuroprotective effects of NMDA receptor antagonists could outweigh the negative short-term sideeffects. Thus the acute use of these compounds may be of considerable therapeutic value. However, the pharmacology of these compounds is complex and more detailed studies regarding their potential side effects in developing animals will be required prior to their use in humans. For example, acute administration of the NMDA receptor antagonist MK-801, at doses required to achieve neuroprotection, may sensitize the developing brain to EAA-mediated brain injury ${ }^{130}$. In contrast to the neuroprotective effects of MK-801 when administered shortly before or after intrastriatal injection of NMDA in PND 7 rats, administration $24 \mathrm{~h}$ before NMDA injection paradoxically enhances NMDA-mediated brain injury. Persistent upregulation of NMDA receptors induced by MK-801 pretreatment may account for the enhanced toxicity of NMDA. Acute administration of MK-801 rapidly upregulates the number of NMDA receptors (within $30 \mathrm{~min} ; 30-50 \%$ increase relative to controls) and this response persists up to $24 \mathrm{~h}^{130,136}$. The persistent increase in the numbers of NMDA receptors may sensitize the brain to injury as the levels of MK-801 decline in the brain. To avoid this problem in clinical practice, it may be necessary to develop therapeutic protocols in which patients are gradually weaned from these compounds.

Although substantial evidence indicates that NMDA rcceptor antagonists may be of therapeutic value in several forms of acute brain injury, few of these antagonists are approved for use in humans. Potential neuroprotective agents that act at the NMDA receptor channel complex and that are approved for human use include ketamine and dextromethorphan (PCP receptor ligands), magnesium and barbitol derivatives. Ketamine, dextromethorphan and barbitol derivatives limit excitotoxic neuronal injury in both the developing and mature brain $^{33,135,136,172,194}$. Although these compounds are less potent and have a smaller therapeutic dose range between neuroprotective and toxic doses than other NMDA antagonists their immediate availability for clinical therapy is exciting. One interesting therapeutic possibility, that has not received much attention, is magnesium sulfate. Magnesium is as effective as several other NMDA receptor antagonists in blocking NMDAmediated brain injury in perinatal rats ${ }^{125,136}$. Furthermore, magnesium protects against hypoxic-ischemic and traumatic CNS injury ${ }^{99,138,193,237}$. Finally, magnesium has been used therapeutically for many years to treat eclamptic seizures $^{31}$. Magnesium normally does not readily 


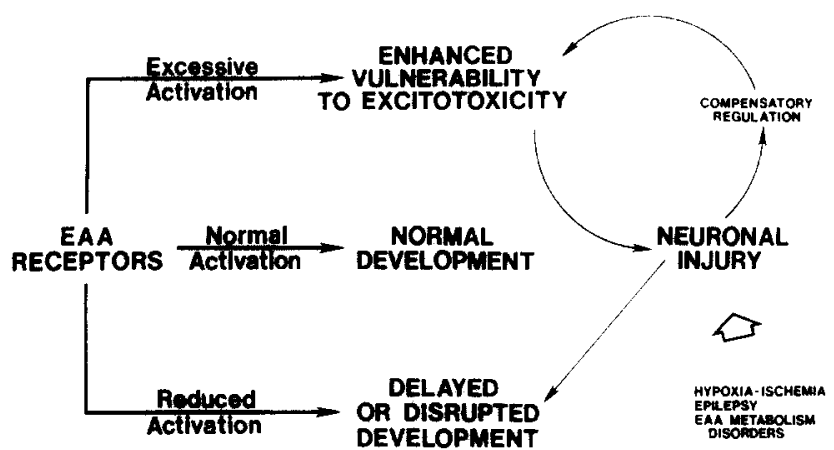

Fig. 10. Schematic diagram relating the level of EAA receptor activation and the balance between normal and delayed or disrupted development and excitotoxicity. Evidence presented in this review suggests there is an optimum level of EAA activation required for normal development. However, excessive receptor activation can produce neuronal injury while under activation may delay or disrupt normal development. Acute brain injury (e.g. hypoxia-ischemia etc.) can directly disrupt the normal course of development. Following brain injury, neuronal adaptive regulatory mechanism are activated. These compensatory processes, while promoting neuronal plasticity and repair, may paradoxically enhance the susceptibility of the brain to excitotoxic injury. A corollary to this phenomena is that the developing brain would be predicted to be most vulnerable to excitotoxic injury during periods when the capacity for synaptic plasticity is greatest.

penetrate the fully developed blood-brain barrier, but the blood-brain barrier permeability is greater in infants, during seizures, in hypoxia-ischemia and in other acute neurologic disorders ${ }^{23,52,62}$. Thus, magnesium may provide effective therapy in these conditions when administered parentally. The experimental evidence of magnesium's neuroprotective properties together with its proven clinical utility in obstetrics and the absence of neurotoxicity suggest that this agent could provide a unique therapeutic approach to limit excitotoxic brain injury in humans.

\subsection{Chronic therapy}

Chronic use of EAA receptor antagonists, especially NMDA receptor antagonists, as therapeutic agents during development (e.g. for treatment of childhood epilepsy) may be considerably limited. Given that EAA receptor activation underlies certain forms of activitydependent synaptic plasticity and regulates the development of cytoarchitecture and neuronal circuitry, the potential long-term side effects of chronic treatment with NMDA receptor antagonists may well far outweigh their benefits. Evidence in humans suggests that chronic administration of PCP produces deleterious behavioral effects in infants ${ }^{98,111,240}$. PCP readily crosses the placental barrier and can also be transferred in breast milk ${ }^{40,155}$. Several studies indicate that administration of PCP to pregnant female rats and sows results in a prolonged fetal exposure; PCP is concentrated in the fetal brain (10-fold greater than the concentration in maternal brain) and
PCP persists in the fetal brain for weeks after PCP is undetectable in the mothers brain or serum ${ }^{40}$. In addition, several case reports in humans suggest that fetal exposure to PCP may produce severe developmental neurologic disorders and PCP may also be teratogenic ${ }^{77}$, 96,225 . Thus the high concentration and persistence of PCP (and potentially its analogues) in the immature brain may affect later CNS development. Exposure of the developing nervous system to PCP appears to produce chronic adverse effects and may potentially interfere with a variety of developmental processes. It is not clear whether competitive NMDA receptor or glycine receptor antagonists will entirely share these properties.

In summary, antagonism of NMDA receptor activation by any of the above pharmacological strategies provides a rational therapeutic approach to limit excitotoxic CNS injury during development. There are many clinical situations in which these antagonists could be used to limit acute brain injury. However, the risks of chronic use of these drugs during childhood may outweigh their potential benefits.

\section{CONCLUSIONS}

The experimental data reviewed here suggest that EAAs participate in a variety of physiological and pathophysiological processes during CNS development. EAAs function as neurotransmitters and also regulate development of neuronal cytoarchitecture and neuronal connectivity. EAAs play a major role in several forms of activity-dependent synaptic plasticity including learning and memory and stabilization and elimination of synaptic connections. However, the same events that underlie these mechanisms may also be transformed into processes that result in neuronal destruction. EAAs may play a role in several developmental neurologic disorders including hypoxic-ischemic and seizure-related brain injury, disorders of amino acid metabolism and neuroendocrinopathies. Thus a critical level of activity of EAA neurotransmitter systems is required for normal CNS development (Fig. 10). Too little activity may delay or impair CNS development while overactivity could produce neuronal damage. Once the brain is injured, adaptive regulatory mechanisms are activated which promote neuronal plasticity and repair. Paradoxically, these compensatory mechanisms may also enhance the susceptibility of the brain to neuronal injury. As a corollary to these phenomena, the developing brain appears to be most susceptible to excitotoxic injury (i.e. NMDA-mediated) during periods of heightened synaptic plasticity. Also, the structures of the mature brain that are most susceptible to neuronal injury correspond to the areas that are believed to have the greatest capacity for synaptic 
plasticity. In accordance with this hypothesis, the susceptibility of individual brain structures to excitotoxic injury changes dramatically during postnatal development. In general, susceptibility to excitotoxicity produced by EAA analogues selective for each EAA receptor subtype transiently peaks during early postnatal development (with the exception of kainate toxicity) and peak toxicity to each analogue occurs at different developmental ages whereas kainate toxicity increases with age. Differences in the developmental expression and regulation of the receptor subtypes may contribute to these ontogenic effects. Thus the regional pattern of neuronal susceptibility to excitotoxicity produced by excessive EAA receptor activation induced by glutamate will be markedly dependent upon developmental age. For these reasons, NMDA and quisqualate/AMPA receptor antagonists may provide more effective therapy against excitotoxic brain injury during development and may become progressively less effective with maturity whereas antagonists of kainate receptors would be more effective in adults. However, the potential for adverse neurological effects produced by chronic blockade of NMDA and quisqualate/AMPA receptors is also greater during early postnatal development. With the advent of selective non-NMDA type EAA receptor antagonists, future studies will delineate the contribution of ionotropic and metabotropic type quisqualate receptors and kainate receptors to the physiology and pathophysiology of CNS development.

\section{SUMMARY}

Recent studies suggest that excitatory amino acids (EAAs) have a wide variety of physiological and pathophysiological roles during central nervous system (CNS) development. In addition to participating in neuronal signal transduction, EAAs also exert trophic

\section{ABBREVIATIONS}

AMPA $\alpha$-amino-3-hydroxy-5-methyl-4-isoxazole proprionate

APV 2-amino-5-phosphonovaleric acid

CNS central nervous system

DG diacylglycerol

DGG $\quad \gamma$-D-glutamylglycine

EAA excitatory amino acid

$\mathrm{IP}_{3}$ inositol-4,5-triphosphate

LTP long-term potentiation

\section{REFERENCES}

1 Ahmad, G., Halsall, L.C. and Bondy, S.C., Persistence of phencyclidine in fetal brain, Brain Research, 415 (1987) 194-196.

2 Altman, J., Postnatal development of the cerebellar cortex in the rat, J. Comp. Neurol., 145 (1972) 465-514.

3 Altman, J., Morphological development of the rat cerebellum influences affecting neuronal survival, growth and differentiation during restricted developmental periods. EAAs also participate in the development and maintenance of neuronal circuitry and regulate several forms of activitydependent synaptic plasticity such as LTP and segregation of converging retinal inputs to tectum and visual cortex. Pre- and post-synaptic markers of EAA pathways in brain undergo marked ontogenic changes. These markers are commonly overexpressed during development; periods of overproduction often coincide with times when synaptic plasticity is great and when appropriate neuronal connections are consolidated. The electrophysiological and biochemical properties of EAA receptors also undergo marked ontogenic changes. In addition to these physiological roles of EAAs, overactivation of EAA receptors may initiate a cascade of cellular events which produce neuronal injury and death. There is a unique developmental profile of susceptibility of the brain to excitotoxic injury mediated by activation of each of the EAA receptor subtypes. Overactivation of EAA receptors is implicated in the pathophysiology of brain injury in several clinical disorders to which the developing brain is susceptible, including hypoxia-ischemia, epilepsy, physical trauma and some rare genetic abnormalities of amino acid metabolism. Potential therapeutic approaches may be rationally devised based on recent information about the developmental regulation of EAA receptors and their involvement in the pathogenesis of these disorders.

Acknowledgements. This work was supported by NIH MSTP Grant 5 T32 6M07863-07 (J.W.M) and grants to M.V.J: NIH P01 NS19613, R01 NS28208 (Javits Neuroscience Investigator Award) and a Basic Research Grant 1145 from the March of Dimes Birth Defects Foundation. The authors thank Drs. H.T. Cline, E.F. Domino, J.B. Penney, F.S. Silverstein, J. Woods and A.B. Young for critical reviews of this manuscript and for many helpful and informative discussions.

MK-801 (+)-5-methyl-10,11-dihydro-5H-dibenzo [a.d] cyclohepten-5,10-imine maleate

NKH non-ketotic hyperglycinemia

NMDA $N$-methyl-D-aspartate

PCP phencyclidine

$\mathrm{PIP}_{2}$ phosphatidyl-4,5-inositolbisphosphate

PND postnatal day

PNW postnatal week

PNY postnatal year

TTX tetrodotoxin

and source of its mechanisms. In V. Chan Palay and S. Palay (Eds.), The Cerebellum: New Vistas, Springer, Berlin, 1982, pp. 8-49.

4 Andine, P., Lehmann, A., Eilren, K., Wennberg, E., Kjeller, I., Nielsen, T. and Hagberg, H., The excitatory amino acid antagonist kynurenic acid administered after hypoxic-ischemia in neonatal rats offers neuroprotection, Neurosci. Lett., 90 (1988) 208-212. 
5 Anglister, L., Farber, I.C., Shahar, A. and Grinvald, A., Localization of voltage-sensitive calcium channels along developing neurites: their possible role in regulating neurite outgrowth, Dev. Biol., 94 (1982) 351-365.

6 Arslan, M., Pohl, C.R. and Plant, T.M., DL-2-amino-5phosphonopentanoic acid, a specific $N$-methyl-D-aspartic acid receptor antagonist, suppresses pusatile LH release in the rat, Neuroendocrinology, 47 (1988) 465-468.

7 Aruffo, C., Ferszt, R., Hildebrandt, A.G. and Cervos-Navarro, J., Low doses of $L$-monosodium glutamate promote neuronal growth and differentiation in vitro, Dev. Neurosci., 9 (1987) 228-239.

8 Ascher, P. and Nowak, L., Electrophysiological studies of NMDA receptors, Trends Neurosci., 10 (7) (1987) 284-288.

9 Balazs, R., Jørgensen, O.S. and Hack, N., N-methyl-Daspartate promotes the survival of cerebellar granule cells in culturc, Neuroscience, 27(2) (1988) 437-451.

10 Balazs, R., Hack, N. and Jørgensen, O.S., Stimulation of the $N$-methyl-D-aspartate receptor has a trophic effect on differentiating cerebellar granule cells, Neurosci. Lett., 87 (1988) 80-86.

10a Balazs, R., Hack, N., Jørgensen, O.S. and Cotman, C.W., $N$-methyl-D-aspartate promotes the survival of cerebellar granule cells: pharmacological characterization, Neurosci. Lett., 101 (1989) 241-246.

11 Balcar, V.J. and Johnson, G.A.R., The structural specificity of the high-affinity uptake of $\mathrm{L}$-glutamate and $\mathrm{L}$-aspartate by rat brain slices, J. Neurochem., 19 (1972) 2657-2666.

12 Barks, J.B., Silverstein, F.S., Sims, K., Greenamyre, J.T. and Johnston, M.V., Glutamate recognition sites in human fetal brain, Neurosci. Lett., 84 (1987) 131-136.

13 Baudry, M., Arst, D., Oliver, M. and Lynch, G., Development of glutamate binding sites and their regulation by calcium in rat hippocampus, Dev. Brain Res., 1 (1981) 37-48.

14 Beal, M.F., Kowall, N.W., Ellison, D.W., Mazurek, M.F., Swartz, K.J. and Martin, J.B., Replication of the neurochemical characteristics of Huntington's disease by quinolinic acid, Nature (Lond.), 321 (1986) 168-172.

15 Ben-Ari, Y., Tremblay, E., Berger, M. and Nitecka, L., Kainic acid seizure syndrome and binding sites in developing rats, Dev. Brain Res., 14 (1984) 284-288.

16 Ben-Ari, Y., Cheruhini, E. and Krnjevic, K., Changes in voltage dependence of NMDA currents during development, Neurosci. Lett., 94 (1988) 88-92.

17 Ben-Ari, Y., Corradetti, R. and Gaiarsa, J.L., Spontaneous and evoked giant EPSPs in neurones from immature rat hippocampal slices involve the acitivation of $N$-methyl-Daspartate (NMDA) receptors, J. Physiol. (Lond.), 406 (1988) $7 \mathbf{p}$.

17a Ben-Ari, Y., Cherubini, E., Corradelli, R. and Gaiarsa, J.-L., Giant synaptic potentials in immature rat CA3 hippocampal neurons, J. Physiol. (Lond.), 416 (1989) 303-325.

18 Benveniste, H., Drejer, J., Schousboe, A. and Diemer, N.H., Elevation of the extracellular concentrations of glutamate and aspartate in rat hippocampus during transient cercbral ischemia monitored by intracerebral microdialysis, J. Neurochem., 43 (1984) 1369-1374.

19 Berger, M. and Ben-Ari, Y., Autoradiographic visualization of $\left[{ }^{3} \mathrm{H}\right]$ kainic acid receptor subtypes in the rat hippocampus, Neurosci. Lett., 39 (1983) 237-242.

20 Block, G.A. and Pulsinelli, W.A., Excitatory amino acid and adenosinergic receptor function in ischemic neuronal death. In G.G. Somejen (Ed.), Mechanisms of Cerebral Hypoxia and Stroke, Plenum, New York, 1989, in press.

21 Bode-Greuel, K.M. and Singer, W. The development of $\mathrm{N}$-methyl-D-aspartate receptors in cat visual cortex, Dev. Brain Res., 46 (1989) 197-204.

22 Bolsover, S.R. and Spector, I., Measurements of calcium transients in the soma, neurite and growth cone of single cultured neurons, J. Neurosci., 6 (1986) 1934-1940.
23 Borges, L.F. and Gucer, G., Effect of magnesium on epileptic foci, Epilepsia, 19 (1978) 81-91.

24 Bowyer, J.F., Phencyclidine inhibition of the rate of kindling development, Exp. Neurol., 75 (1982) 173-183.

25 Brady, R.J. and Swann, J.W., Ketamine selectively suppresses synchronized afterdischarges in immature hippocampus, $\mathrm{Neu}$ rusci. Lelt., 69 (1986) 143-149.

26 Brady, R.J. and Swann. J.W., The effects of extracellular calcium on the epileptiform activity and NMDA responses are different in mature and immature hippocampal slices, Soc. Neurosci. Abstr., 14 (1988) 98.7.

26a Brewer, G.J. and Cotman, C.W., NMDA receptor regulation of neuronal morphology in cultured hippocampal neurons, Neurosci. Lett. 99 (1989) 268-273.

26b Bulloch, A.G.M., Sprouting by intact Helisoma neurons: role for glutamate, J. Neurosci. Res. 23 (1989) 384-395.

27 Burdc, R.M., Schainker, B. and Kaycs, J., Acutc effect of oral and subcutaneous administration of monosodium glutamate on the arcuate nucleus of the hypothalamus in mice and rats, Nature (Lond.), 233 (1971) 58-60.

28 Campochiaro, P. and Coyle, J.T., Ontogenic development of kainate neurotoxicity: correlates with glutamatergic innervation, Proc. Natl. Acad. Sci. U.S.A., 75 (4) (1978) 2025-2029.

29 Carson, N.A.J., Non-ketotic hyperglycinaemia-A view of 70 patients, J. Inherited Metab. Dis., 5 Suppl. 2 (1982) 126-128.

30 Chang, F.L.F. and Greenough, W.T., Transient and enduring morphological correlates of synaptic activity and efficacy change in the rat hippocampal slice, Brain Research, 309 (1984) $35-46$.

31 Chelsey, L.C., Hypertensive Disorders in Pregnancy, AppletonCentury-Crofts, New York, 1978.

32 Choi, D.W., Glutamate neurotoxicity and diseases of the nervous system, Neuron, 1 (1988) 623-634.

33 Choi, D.W., Dextrorphan and levorphanol selectively block $\mathrm{N}$-methyl-D-aspartate receptor-mediated neurotoxicity in cortical neurons, J. Pharmacol. Exp. Ther., 242 (1987) 713-720.

33a Chen, C.-K., Silverstein, F.S., Fisher, S.K., Statman, D. and Johnston, M.V., Perinatal hypoxic-ischemic brain injury enhances quisqualic acid-stimulated phosphoinositide turnover, $J$. Neurochem., 151 (1988) 353-359.

33b Chen, C., Statman, D., Silverstein, F.S. and Johnston, M.V., Ouisqualic acid and its analogue AMPA enhances phosphoinositide turnover in $N$-methyl-D-aspartate lesioned brain of perinatal rats. Soc. Neurosci. Abstr., 14 (1988) 420.

34 Cicero, T.J., Meyer, E.R. and Bell, R.D., Characterization and possible opioid modulation of $N$-methyl-D-aspartic acid induced increases in serum luteinizing hormone levels in the developing male rat, Life Sci., 42 (1988) 1725-1732.

34a Clifford, D.B., Zorumski, C.F. and Olney, J.W., Ketamine and MK- 801 prevent degencration of thalamic neurons induced by focal cortical seizures, Exp. Neurol., 105 (1989) 272-279.

35 Cline, H.T., Debski, E.A. and Constantine-Paton, M., $N$ methyl-D-aspartate receptor antagonist desegregates eye-specific stripes, Proc. Natl. Acad. Sci. U.S.A., 84 (1987) 43424345.

35a Cline, H.T. and Constantine-Paton, M., NMDA receptor antagonists disrupt the retionotectal topographic map, Neuron, 3 (1989) 413-426.

35b Cline, H.T. and Constantine-Paton, NMDA receptor agonist and antagonists alter RGC, terminal morphology in the frog retinotectal projection, $J$. Neurosci, in press.

36 Collingridge, G.L. and Bliss, T.V., NMDA receptors - their role in long-term potentiation, Trends Neurosci., 10 (1987) 288-293.

37 Connor, J.A., Digital imaging of free calcium changes and of spatial gradients in growing processes in single, mammalian central nervous system cells, Proc. Natl. Acad. Sci. U.S.A., 83 (1986) 6179-6183.

38 Collins, R.C. and Olney, J.W., Focal cortical seizures cause distant thalamic lesions, Science, 218 (1982) 177-179. 
39 Cook, T.M. and Crutcher, K.A., Intrahippocampal injection of kainic acid produces significant pyramidal cell loss in neonatal rats, Neurosci., 18 (1) (1986) 79-92.

40 Cooper, J.E., Cummings, A.J. and Jones, H., The placental transfer of phencyclidine in the pig: plasma levels in the sow and its piglets, J. Physiol. (Lond.), 267 (1977) 17.

41 Cotman, C., Taylor, D. and Lynch, G., Ultrastructural changes in synapses in the dentate gyrus of the rat during development, Brain Research, 6 (1973) 205-213.

42 Cotman, C.W., Monaghan, D.T, Ottersen, O.P. and StormMathisen, J., Anatomical organization of exitatory amino acid receptors and their pathways, Trends Neurosci., 10 (1987) 273-279.

43 Cotman, C.W. and Iversen, L.L., Excitatory amino acids in the brain - focus on NMDA receptors, Trends Neurosci., 10 (1987) 263-265.

44 Cowan, W.M., Fawcett, J.W., O'Leary, D.D.M. and Stanfield, B.B., Regressive events in neurogenesis, Science, 225 (1984) 1258-1265.

45 Coyle, J.T., Neurotoxic action of kainic acid, J. Neurochem., 4 (1983) 1-11.

46 Coyle, J.T and Schwarcz, R., Lesion of striatal neurons with kainic acid provides a model for Huntington's chorea, Nature (Lond.), 263 (1976) 244-246.

47 Crain, B., Cotman, C., Taylor, D. and Lynch, G., A quantitative electronmicroscopic study of synaptogenesis in the dentate gyrus of the rat, Brain Research, 63 (1973) 194-204.

48 Croucher, M.J., Collins, J.F. and Meldrum, B.S., Anticonvulsant action of excitatory amino acid antagonists, Science, 216 (1982) 899-901.

49 Croucher, M.J., Bradford, H.F., Sunter, D.C. and Watkins, J.C., Inhibition of the development of electrical kindling of the prepyriform cortex by daily focal injections of excitatory amino acid antagonists, Eur. J. Pharmacol., 152 (1988) 29-38.

50 Cunningham, T.J., Naturally occurring neuron death and its regulation by developing neural pathways, Int. Rev. Cytol., 74, (1982), 163-186.

51 Curtis, D.R. and Johnston, G.A.R., Amino acid transmitters in the mammalian central nervous system, Ergeb. Physiol., 69 (1974) 98-108.

52 Cutler, R.W.P., Lorenzo, A.V. and Barlow, C.F, Changes in blood-brain barrier permeability during pharmacologically induced convulsions, Brain Research, 29 (1968) 367-384.

52a Cynader, M., Prolonged sensitivity to monocular deprivation in dark-reared cats: effects of age and visual exposure, Dev. Brain Res., 8(1983) 155-164.

53 Czuczwar, S.J. and Meldrum, B.S., Protection against chemically induced seizures by 2-amino-7-phosphonoheptanoic acid, Eur. J. Pharmacol., 83 (1982) 335-338.

53a Debski, E.A., Cline, H.T. and Constantine-Paton, M., Chronic application of NMDA or APV affects the NMDA sensitivity of the evoked tectal responses in Rana pipiens, Soc. Neurosci. Abst., 15 (1989) 495.

54 Do, K.Q., Herrling, P.L., Streit, P., Turski, W.A. and Cuenod, M., In vitro release and electrophysiological effects in situ of homocysteic acid, an endogenous $N$-methyl-(D)-aspartic acid agonist, in the mammalian striatum. J. Neurosci., 6 (1986) 2226-2234

55 Drejer, J., Benveniste, H., Diemer, N.H. and Schousboe, A., Cellular origin of ischemia-induced glutamate release from brain tissue in vivo and in vitro, $J$. Neurochem., 45 (1985) 145-151.

55a Dudek, S.M. and Bear, M.F., A biochemical correlate of the critical period for synaptic modification in the visual cortex, Science, 246 (1989) 673-675.

56 Duffy, C.J. and Teyler, T.J., Development of potentiation in the dentate gyrus of rat: physiology and anatomy, Brain Research Bull, 3 (1978) 425-430.

57 Dupont, J., Gardette, R. and Crepel, F., Postnatal development of the chemosensitivity of rat cerebellar Purkinje cells to excitatory amino acids. An in vitro study, Dev. Brain Res., 34 (1987) 59-68.

58 Engelsen, B, Neurotransmitter glutamate: its clinical importance, Acta Neurol. Scand., 74 (1986) 337-355.

59 Everly, J.L., Light microscopic examination of MSG-induced lesions in brain of fetal and neonatal rats, Anat. Rec., 169 (1971) 312.

60 Faden, A.I. and Simon, R.P., A potential role for excitotoxins in the pathophysiology of spinal cord injury, Ann. Neurol., 23 (6) (1988) 623-626.

61 Fagg, G.E. and Foster, A.C., Amino acid neurotransmitters and their pathways in the mammalian central nervous system, Neurosci., 9 (1983) 701-719.

62 Fishman, R.A., Neurological aspects of magnesium metabolism, Arch. Neurol., 12 (1965) 562-569.

63 Flatman, J.A., Schwindt, P.C., Crill, W.E. and Afstrom, S.T., Multiple actions of $N$-methyl-D-aspartate on cat neocortical neurons in vitro, Brain Research, 226 (1983) 169-173.

64 Fonnum, F., Glutamate: a neurotransmitter in mammalian brain, J. Neurochem., 42 (1984) 1-11.

65 Fosse, V.M., Heggelund, P. and Fonnum, F., Postnatal development of glutamatergic, GABAergic and cholinergic neurotransmitter phenotypes in the visual cortex, lateral geniculate nucleus, pulvinar and superior colliculus in cats, $J$. Neurosci. (9)2 (1989) 426-435.

66 Foster, A.C., Collins, J.F. and Schwarcz, R., On the excitotoxic properties of quinolinic acid, 2-3-piperidine dicarboxylic acids and structurally related compounds, Neuropharmacology, 22 (1983) 1331-1342.

67 Foster, A.C., Gill, R., Kemp, J.A. and Woodruff, G.N., Systemic administration of $\mathrm{MK}-801$ prevents $N$-methyl-Daspartate induced neuronal degeneration in rat brain, Neurosci. Lett., 76 (1987) 307-311.

67a Fox, K., Sato, H. and Daw, N., The location and function of NMDA receptors in cat and kitten visual cortex, J. Neurosci., 9 (1989) 2443-2454.

67b Freeman, R.D. and Bonds, A.B., Cortical plasticity in monocularly deprived immobilized kittens depends on eye movement, Science, 206 (1979) 1093-1095.

68 Frotscher, M. and Zimmer, J., Intracerebral transplants of the rat fascia dentata: a Golgi/electron microscope study of dentate granule cells, J. Comp. Neurol., 246 (1986) 181-190.

69 Ganong, A.H. and Cotman, C.W., Kynurenic acid and quinolinic acid act at $N$-methyl-D-aspartate receptors in the rat hippocampus, J. Pharmacol. Exp. Ther., 236 (1985) 293-299.

70 Garthwaite, G. and Garthwaite, J., In vitro neurotoxicity of excitatory acid analogues during cerebellar development, $\mathrm{Neu}$ rosci., 17 (3) (1986) 755-767.

71 Garthwaite, G., Yamini Jr., B. and Garthwaite, J., Selective loss of Purkinje and granule cell responsiveness to $\mathrm{N}$-methylD-aspartate in rat cerebellum during development, Dev. Brain Research, 36 (1987) 288-292.

72 Gay, V.L, and Plant, T.M., N-methyl-DL-aspartate (NMA) elicits hypothalamic GnRH release in prepubertal male rhesus monkeys (Macaca mulatta), Endocrinology, 120 (1987) 22892296.

73 Gay, V.L. and Plant, T.M., Sustained intermittent release of gonadotropin-releasing hormone in the prepubertal male rhesus monkey induced by $\mathrm{N}$-methyl-DL-aspartic acid, Neuroendocrinology, 48 (1988) 147-152.

74 Gerritsen, T, Kaveggia, E. and Waisman, H.A., A new type of idiopathic hyperglycinemia with hypooxaluria, Pediatrics, 36 (1965) 882-891.

75 Gilbert, M.E., The NMDA-receptor antagonist, MK-801, suppresses limbic kindling and kindled seizures, Brain Research, 463 (1988) 90-99.

76 Gill, R., Foster, C. and Woodruff, G.N., Systemic administration of MK-801 protects against ischemia-induced hippocampal neurodegeneration in the gerbil, $J$. Neurosci., 7 (1987) 33433349 . 
77 Golden, N.L., Sokol, R.J. and Rubin, I.L., Angel dust: possible effects on the fetus, Pediatrics, 65 (1) (1980) 18-20.

78 Greenamyre, J.T., Olson, J.M.M., Penney, J.B. and Young, A.B., Autoradiographic characterization of $N$-methylD-aspartate, quisqualate and kainate-sensitive glutamate binding sites, J. Pharmacol. Exp. Ther., 233 (1985) 254-263.

79 Greenamyre, J.T., The role of glutamate in neurotransmission and in neurologic disease, Arch. Neurol., 43 (1986) 1058-1063.

80 Greenamyre, J.T., Penney, J.B., Young, A.B., Hudson, C., Silverstein, F.S. and Johnston, M.V., Evidence for transient perinatal glutamatergic innervation of globus pallidus, $J$. Neurosci., 7(4) (1987) 1022-1030.

81 Haglund, M.M. and Schwartzkroin, P.A., Seizure-like spreading depression in immature rabbit hippocampus in vitro, Dev. Brain Res., 14 (1984) 51-59.

82 Hamburger, V. and Oppenheimer, R.W., Naturally occurring neuronal death in vertebrates, Neurosci. Commun., 1 (1982) $39-55$.

83 Hamon, B. and Heinemann, U., Developmental changes in neuronal sensitivity to excitatory amino acids in area CA1 of the rat hippocampus, Dev. Brain Res., 38 (1988) 286-290.

84 Hansen, A.J., Effect of anoxia on ion distribution in the brain, Physiol. Rev., 65 (1985) 101-148.

85 Harris, K.M., Teyler, T.J. and Cruce, W.L.R., A developmental comparison of LTP in area CA1 and fascia dentata of the rat hippocampal formation, Soc. Neurosci. Abstr., 6 (1980) 31.7.

86 Harris, K.M. and Teyler, T.J., Evidence for late development of inhibition in area CA1 of the rat hippocampus, Brain Research, 268 (1983) 339-343.

87 Harris, K.M. and Teyler, T.J., Developmental onset of longterm potentiation in area CA1 of the rat hippocampus, $J$. Physiol. (Lond.), 346 (1984) 27-48.

88 Hasting, M.H., Winn, P. and Dunnett, S.B., Neurotoxic amino acid lesions of the lateral hypothalamus: a parametric comparison of the effects of ibotenate, $N$-methyl-D,L-aspartate and quisqualate in the rat, Brain Research, 360 (1985) 248-256.

89 Herron, C.E., Lester, R.A.J., Coan, E.J. and Collingridge, G.L., Intracellular demonstration of an $N$-methyl-b-aspartate receptor mediated component of synaptic transmission in rat hippocampus, Neurosci. Lett., 60 (1985) 19-23.

90 Hubel, D.H. and Wiesel, T.N., The period of susceptibility to the physiological effects of unilateral eye closure in kittens, $J$. Physiol. (Lond.), 206 (1970) 419-436.

91 Huttenlocher, P.R., Synaptic density in human frontal cortexdevelopmental changes and effects of aging, Brain Research, 163 (1979) 195-205.

91a Iadarola, M.J., Nicoletti, F., Naranjo, J.R., Putman, F. and Costa, E., Kindling enhances the stimulation of inositol phospholipid hydrolysis elicited by ibotenic acid in rat hippocampal slices, Brain Research, 374 (1986) 174-178.

92 Ikonomidou, C., Mosinger, J.L., Shahid Salles, K., Labruyere, J. and Olney, J.W., Sensitivity of the developing rat brain to hypobaric/ischemic damage parallels sensitivity to $N$-methylD-aspartate neurotoxicity, $J$. Neurosci., 9 (1989) 2809-2818.

93 Irreverre, F., Mudd, S.H., Heizer, W.D. and Laster, L., Sulfite oxidase deficiency, Biochem. Med., 1 (1967) 187-217.

94 Johansen, F.F., Jørgensen, M.B. and Diemer, N.H., Ischemic CA-1 pyramidal cell loss is prevented by preischemic colchicine destruction of dentate gyrus granule cells, Brain Research, 377 (1986) 344-347.

95 Johnson, J.W. and Ascher, P., Glycine potentiates the NMDA response in cultured mouse brain neurons, Nature (Lond.), 325 (1987) 529-531.

96 Jordan, R.L., Young, T.R. and Harry, G.J., Teratology of phencyclidine in rats: preliminary studies, Teratology, 17 (1978) A 40 .

97 Jørgensen, M.B., Johansen, F.F. and Diemer, N.H., Removal of the entorhinal cortex protects hippocampal CA-1 neurons from ischemic damage, Acta Neuropathol. (Berl), 73 (1987) 189-194.
98 Karp, H.N., Kaufman, N.D. and Anand, S.K., Phencyclidine poisoning in young children, J. Pediatr., $97(1980) 1006$.

99 Kass, I.S., Cottrell, J.E. and Chambers, G., Magnesium and cobalt, not nimodipine, protect neurons against anoxic damage in the rat hippocampal slice, Anesthesiology, 69 (1988) 710715 .

100 Kemp, J.A., Foster, A.C. and Wong, E.H.F., Non-competitive antagonists of excitatory amino acid receptors, TINS, 10(7) (1987) 294-299

101 King, A.E., Cherubini, E. and Ben-Ari, Y., N-methyl-Daspartate induces recurrent synchronized burst activity in immature hippocampal CA3 neurones in vitro, Dev. Brain Res., 46 (1989) 1-8.

102 Kleckner, N.W. and Dingledine, R., Requirement for glycine in activation of NMDA receptors expressed in xenopus oocytes, Science, 241 (1988) 835-837.

103 Kleinschmidt, A., Bear, M.F. and Singer, W., Blockade of 'NMDA' receptors disrupts experience-dependent plasticity of kitten striate cortex, Science, 238 (1987) 355-358.

104 Kohler, C. and Schwarcz, R., Monosodium glutamate: increased neurotoxicity after removal of neuronal re-uptake sites, Brain Research, 211 (1981) 485-491.

105 Kornhuber, J., Retz, W., Riederer, P., Heinsen, H. and Fritze, J., Effect of antemortem and postmortem factors on $\left[{ }^{3}\right.$ H]glutamate binding in the human brain, Neurosci. Lett., 93 (1988) 312-317.

106 Kvale, I., Fosse, V.M. and Fonnum, F., Development of neurotransmitter parameters in lateral geniculate body, superior colliculus and visual cortex of the albino rat, Dev. Brain Res., 7 (1983) 137-145.

107 Labuyere, J., Fuller, T.A., Olney, J.W., Price, M.T., Zorumski, C. and Clifford, D., Phencyclidine and ketamine protect against kainic acid-induced seizure related damage, Soc. Neurosci. Abstr., 12 (1986) 344.

108 Larson, A.A. and Beitz, A.J., Glycine potentiates strychnineinduced convulsions: role of NMDA receptors. $J$. Neurosci., 8 (1988) 3822-3826.

109 Laurberg, S. and Zimmer, J., Lesion-induced sprouting of hippocampal mossy fiber collaterals to the fascia dentata in developing and adult rats, $J$. Comp. Neurot., 200 (1981) 433-459.

110 Lincoln, J., Coopersmith, R., Harris, E.W., Cotman, C.W. and Leon, M., NMDA receptor activation and early olfactory learning, Dev. Brain Res., 39 (1988) 309-312.

111 Linden, C.B., Lovejoy, F.H and Costello, C.E., Phencyclidine (Serrylan) poisoning, J. Pediatr., 83 (1973) 844.

112 Loy, R., Lynch, G. and Cotman, C., Development of afferent lamination in the fascia dentata of the rat, Brain Res., 121 (1977) 229-243.

113 Loy, R., Development of afferent lamination in Ammon's horn of the rat, Anat. Embryol., 159 (1980) 257-275.

114 MacDermott, A.B., Mayer, M.L., Westbrook, G.L., Smith, S.J. and Barker, J.L., NMDA-receptor activation increases cytoplasmic calcium concentration in cultured spinal cord neurons, Nature (Lond.), 321 (1986) 519-522.

115 Macdonald, J.F., Porietis, A.V. and Wojtowicz, J.M., Lglutamic acid induces a region of negative slope conductance in the current-voltage relationship of cultured spinal cord neurons, Brain Research, 237 (1982) 248-253.

116 Maragos, W.F, Greenamyre, J.T., Penney, J.B. and Young, A.B., Glutamate dysfunction in Alzheimer's disease: a hypothesis, TINS, 10 (1987) 65-67.

117 Martin, D. and Lodge, D., Ketamine acts as a non-competitive $\mathrm{N}$-methyl-D-aspartate antagonist on frog spinal cord in vitro, Neuropharmacology, 24 (1985) 999-1003.

118 Mattson, M.P., Neurotransmitters in the regulation of neuronal cytoarchitecture, Brain Res. Rev., 13 (1988) 179-212.

119 Mattson, M.P., Lee, R.E., Adams, M.E., Guthrie, P.B. and Kater, S.B., Interactions between entorhinal axons and target hippocampal neurons: a role for glutamate in the development 
of hippocampal circuitry, Neuron, 1 (1988) 865-876.

120 Mattson, M.P., Dou, P. and Kater, S.B., Outgrowth-regulating actions of glutamate in isolated hippocampal pyramidal neurons, J. Neurosci., 8 (6) (1988) 2087-2100.

121 Mayer, M.L., Westbrook, G.L. and Guthrie, P.B., Voltagedependent block by $\mathrm{Mg}^{2+}$ of NMDA responses in spinal cord neurons, Nature (Lond.), 309 (1984) 261-263.

122 Mayer, M.L. and Westbrook, G.L., The physiology of excitatory amino acids in the vertebrate central nervous system, Prog. Neurobiol., 28 (1987) 197-276.

123 McBean, G.J. and Roberts, P.J., Neurotoxicity of L-glutamate and DL-threo-3-hydroxyaspartate in the rat striatum, $J$. Neurochem., 44 (1985) 247-254.

124 McDonald, J.W., Silverstein, F.S. and Johnston, M.V., MK-801 protects the neonatal brain from hypoxic-ischemic damage, Eur. J. Pharmacol., 140 (1987) 359-361.

125 McDonald, J.W., Silverstein, F.S. and Johnston, M.V., Comparison of neuroprotective effects of competitive and noncompetitive NMDA antagonists against NMDA mediated neurotoxicity in an in vivo perinatal rat model. In E.A. Cavalheiro, J. Lehmann and L. Turski (Eds.), Recent Advances in Excitatory Amino Acid Research, Neurology and Neurobiology, Alan R. Liss, New York, 1988, pp. 601-604.

126 McDonald, J.W., Silverstein, F.S., Cardona, D., Uckele, J., Chen, R. and Johnston, M.V., Neuroprotective effects of MK-801 and other compounds on perinatal hypoxic-ischemic injury. In E.F. Domino and K-M. Kamenka (Eds.), In Sigma Opioid-PCP like Compounds As Molecular Probes in Biology, NPP Press, Ann Arbor, 1988, pp. 697-708.

127 McDonald, J.W., Silverstein, F.S. and Johnston, M.V., Neurotoxicity of $N$-methyl-D-aspartate is markedly enhanced in developing rat central nervous system, Brain Research, 459 (1988) 200-203.

128 McDonald, J.W., Cline, H.T., Constantine-Paton, M., Maragos, W.F., Johnston, M.V. and Young, A.B., Quantitative autoradiographic localization of NMDA, quisqualate and PCP receptors in the frog tectum, Brain Research, 482 (1988) 155-158.

129 McDonald, J.W., Uckele, J., Silverstein, F.S. and Johnston, M.V., HA-966 (1-hydroxy-3-aminopyrrolidone-2) selectively reduces $N$-methyl-D-aspartate (NMDA)-mediated brain damage, Neurosci. Lett., 104 (1989) 167-170.

130 McDonald, J.W., Silverstein, F.S. and Johnston, M.V., MK-801 pretreatment enhances NMDA-mediated brain injury and increases brain NMDA recognition site binding in rats, $\mathrm{Neu}$ roscience, (1989) in press.

131 McDonald, J.W., Silverstein, F.S., Cardona, D., Hudson, C., Chen, R. and Johnston, M.V., Systemic administration of MK-801 protects against $N$-methyl-D-aspartate and quisqualate mediated neurotoxicity in perinatal rats, Neuroscience, (1989) in press.

132 McDonald, J.W., Silverstein, F.S. and Johnston, M.V., Neuroprotective effects of MK-801, TCP, PCP and CPP against $\mathrm{N}$-methyl-D-aspartate induced neurotoxicity in an in vivo perinatal rat model, Brain Research, 490 (1989) 33-40.

133 McDonald, J.W., Hood, T., Sackellares, C., Garofalo, E.A., Khahil, B., McKeever, P., Gilman, S., Troncoso, J. and Johnston, M.V., Temporal lobe epilepsy: excitatory and inhibitory amino acid receptor-binding changes in excised hippocampus, Epilepsia, 30 (1989) 719.

$134 \mathrm{McDonald}$, J.W., Johnston, M.V. and Young, A.B., Ontogeny of the receptors comprising the NMDA receptor channel complex, Soc. Neurosci. Abstr., 15 (1989) 86.3.

135 McDonald, J.W., Roeser, N.F., Silverstein, F.S. and Johnston, M.V., Quantitative assessment of neuroprotection against NMDA-induced brain injury, Exp. Neurol., 106 (1989) 289296.

136 McDonald, J.W., Pharmacology of $N$-methyl-D-aspartate toxicity in the developing central nervous system, Doctoral dissertation, University of Michigan, MI, 1989. 136a McDonald, J.W. and Johnston, M.V., Non-ketotic hyperglycinemia: pathophysiological role of NMDA type excitatory amino acid receptors, Ann. Neurol., (1990) in press.

137 McGeer, E.G. and McGeer, P.L., Duplication of biochemical changes of Huntington's chorea by intrastriatal injections of glutamate and kainic acids, Nature (Lond.), 263 (1976) 517519.

138 McIntosh, T.K., Vink, R., Yamakami, I. and Faden, A.I., Magnesium protects against neurological deficit after brain injury, Brain Research, 482 (1989) 252-260.

139 McNamara, J.O., Russell, R.D., Rigsbee, L. and Bonhaus, D.W., Anticonvulsant and anticpileptogenic actions of MK-801 in the kindling and electroshock models, Neuropharmacology, 22 (1988) 563-568.

140 Meldrum, B.S., Possible therapeutic applications of antagonists of excitatory amino acid neurotransmitters, Clin. Sci., 68 (1985) 113-122.

141 Miles, R. and Wong, R.K.S., Single neurons can initiate synchronized population discharges in the $\mathrm{CA} 3$ region of quinea pig hippocampus, Nature (Lond.), 306 (1983) 371-373.

142 Miles, R., Wong, R.K.S. and Traub, R.D., Synchronized afterdischarges in the hippocampus: contribution of local interactions, Neuroscience, 12 (1984) 1179-1189.

142a Miller, K.D., Chapman, B. and Stryker, M.P., Visual responses in adult cat visual cortex depend on $N$-methylD-aspartate receptors, Proc. Natl. Acad. Sci. U.S.A., 86 (1989) 5183-5187.

143 Mollgard, K., Diamond, M.C., Bennett, E.L., Rosenzweig, M.R. and Linder, R., Quantitative synaptic changes with differential experience in rat brain, Int. J. Neurosci., 2 (1971) $113-128$.

144 Monaghan, D.T. and Cotman, C.W., The distribution of $\left[{ }^{3} \mathrm{H}\right]$ kainic acid binding sites in rat CNS as determined by autoradiography, Brain Research, 252 (1982) 91-100.

145 Monaghan, D.T., Holets, V.R., Toy, D.W. and Cotman, C.W., Anatomical distribution of 4 pharmacologically distinct $3 \mathrm{H}$ L-glutamate binding sites, Nature (Lond.), 306 (1983) 176-179.

146 Monaghan, D.T., Bridges, R.J. and Cotman, C.W., The excitatory amino acid receptors: their classes, pharmacology and distinct properties in the function of the central nervous system, Annu. Rev. Pharmacol. Toxicol., 29 (1989) 365-402.

147 Mudd, S.H., Irreverre, F. and Laster, L., Sulfite oxidase deficiency in man: demonstration of the enzymatic defect, Science, 156 (1967) 1599-1602.

148 Murakami, $U$. and Inouye, M., Brain lesions in the mouse fetus caused by maternal administration of monosodium glutamate, Congenital Anomalies, 11 (1971) 171-177.

149 Nadler, J.V., Perry, B.W. and Cotman, C.W., Intraventricular kainic acid preferentially destroys hippocampal pyramidal cells, Nature (Lond.), 271 (1978) 676-677.

150 Nadler, J.V., Perry, B.W., Gentry, C. and Cotman, C.W., Loss and reacquisition of hippocampal synapses after selective destruction of CA3-CA4 afferents with kainic acid, Brain Research, 191 (1980) 387-403.

151 Nadler, J.V., Perry, B.W. and Cotman, C.W., Selective reinnervation of hippoccampal area CA1 and the fascia dentata after destruction of CA3-CA4 afferents with kainic acid, Brain Research, 182 (1980) 1-9.

152 Naito, S. and Ueda, T., Adenosine triphosphate-dependent uptake of glutamate into protein I-associated vesicles, J. Biol. Chem., 258 (1983) 698-699.

153 Nelson, P.G., Brenneman, D.E., Forsythe, I., Nicol, T. and Westbrook, G., NMDA antagonists increase neuronal death without blocking electrical activity in developing cultures, Soc. Neurosci. Abstr., 13 (1987) 9.

154 Nemeroff, C.B., Effects of neurotoxic excitatory amino acids on neuroendocrine regulation. In $K$. Fuxe, P. Roberts and R. Schwartz (Eds.), Excitotoxins, MacMillan Press, London, 1983, pp. 295-305.

155 Nicholas, J.M., Lipshitz, J. and Schreiber, E.C., Phency- 
clidine, its transfer across the placenta as well as into breast milk, Am. J. Obstet. Gynecol, 143 (1982) 143-146.

156 Nicoletti, F., Iadarola, M.J., Wroblewski, J.T. and Costa, E., Excitatory amino acid recognition sites coupled with inositol phospholipid metabolism: developmental changes and interaction with $\alpha$-adrenoceptors, Proc. Natl. Acad. Sci., 83 (1986) 1931-1935.

157 Nicoletti, F., Wroblewski, J.T., Novelli, A., Alho, H., Guidotti, A. and Costa, E., The activation of inositol phospholipid metabolism as a signal-transducing system for excitatory amino acids in primary cultures of cerebellar granule cells, J. Neurosci., 6 (1986) 1905-1911.

157a Nicoletti, F., Wroblewski, J.T., Alho, H., Eva, C., Fadda, E. and Costa, E. Lesions of putative glutamatergic pathways potentiate the increase of inositol phospholipid hydrolysis elicited by excitatory amino acids, Brain Research, 436 (1987) 103-112.

158 Nicoll, R.A., Kauer, J.A. and Malenka, R.C., The current excitement in long-term potentiation, Neuron, 1 (1988) 97-103.

159 Novelli, A., Reilly, J.A., Lysko, P.G. and Henneberry, R.C., Glutamate becomes neurotoxic via the $N$-methyl-D-aspartate receptor when intracellular energy levels are reduced, Brain Res., 451 (1988) 205-212.

160 Nowak, L., Bregestovski, P., Ascher, P., Herbert, A. and Prochiants, A., Magnesium gates glutamate-activated channels in mouse central neurons, Nature (Lond.), 307 (1984) 462-465.

161 Oka, J.I., Metherate, R.S. and Hicks, T.P., Excitatory amino acid antagonists and synaptic transmission in the cat's intact thalamo-cortical somatosensory pathway. In T.P. Hicks, D. Lodge and H. McLennan (Eds.), Excitatory Amino Acid Transmission, Neurology and Neurobiology, Alan R. Liss, New York, 1987, pp. 401-404

162 Olney, J.W., Brain lesions, obesity and other disturbances in mice treated with monosoduim glutamate, Science, 164 (1969) 719-721.

163 Olney, J.W., Ho, O.L. and Rhee, V., Cytotoxic effects of acidic and sulphur containing amino acids on the infant mouse central nervous system, Exp. Brain Res., 14 (1971) 61-76.

164 Olney, J.W., Glutamate-induced neuronal necrosis in the infant mouse hypothalamus: an electron microscopic study, J. Neuropathol. Exp. Neurol., 30 (1971) 75-90.

165 Olney, J.W., Sharpe, L.G. and Feigin, R.D., Glutamateinduced brain damage in infant primates, J. Neuropathol. Exp. Neurol., 31 (1972) 464-488.

166 Olney, J.W., Ho, O.L., Rhee, V. and De Gubareff, T. Neurotoxic effects of glutamate, New Engl. J. Med., 289 (1973) 1374-1375.

167 Olney, J.W., Toxic effects of glutamate and related amino acids on the developing central nervous system. In W.N. Nyhan (Ed.), Ileritable disorders of amino acid metabolism, John Wiley, New York, 1974.

168 Olney, J.W., Misra, C.H. and De Gubareff, T., Cysteine$s$-sulfate: brain damaging metabolite in sulfite oxidase deficiency, J. Neuropathol. Exp. Neurol., 34 (1975) 167-177.

169 Olney, J.W., Cicero, T.J., Meyer, E.R. and De Gubareff, T., Acute glutamate-induced elevations in serum testosterone and luteinizing hormone, Brain Research, 112 (1976) 420-424.

170 Olney, J.W., Fuller, T. and De Gubareff, T., Acute dendrotoxic changes in the hippocampus of kainate-treated rats, Brain Research, 176 (1979) 91-100.

171 Olney, J.W. and Price, M.T., Neuroendocrine interactions of excitatory and inhibitory amino acids, Brain Res. Bull., 5 (1980) 361-368.

172 Olney, J.W., Price, M.T., Fuller, T.A., Labruyere, J., Samson, L., Carpenter, M. and Mahan, K.. The anti-excitotoxic effects of certain anesthetics, analgesics and sedative-hypnotics, $\mathrm{Neu}$ rosci. Lett., 68 (1986) 29-34.

173 Olney, J.W., Ikonomidou, C., Mosinger, J., Shahid Salles, K. and Frierdich, G., Role of the $N$-methyl-D-aspartate receptor in developmental psychoneuropharmacology, Soc. Neurosci. Ab- str., 14 (1988) 417

174 Olson, C.R. and Freeman, R.D., Profile of the sensitive period for monocular deprivation in kittens, Exp. Brain Res., 39 (1980) 17-21.

175 Ondo, J.G., Wheeler, D.D. and Dom, R.M., Hypothalamic site of action for $N$-methyl-D-aspartate (NMDA) on LH sccrction, Life Sci., 43 (1988) 2283-2286.

176 Onodera, H., Sato, G. and Kogure, K., Lesions to Schaffer collaterals prevent ischemic death of CA1 pyramidal cells, Neurosci. Lett., 68 (1986) 169-174.

176a Palmer, E., Monaghan, D.T. and Cotman, C.W., Glutamate receptors and phosphoinositide metabolism: stimulation via quisqualate receptors is inhibited by $N$-methyl-D-aspartate receptor activation, Mol. Brain Res., 4 (1988) 161-165.

177 Parnavelas, J.R., Globus, A. and Kaups, P., Continuous illumination from birth affects spine density of neurons in the visual cortex of the rat, Exp. Neurol., 40 (1973) 742-747.

178 Pearce, I.A., Cambray-Deakin, M.A. and Burgoyne, R.D., Glutamate acting on NMDA receptors stimulates neurite outgrowth from cerebellar granule cells, FEBS Lett., 223 (1987) 143-147.

179 Peters, S., Koh, J. and Choi, D.W., Zinc selectively blocks the action of $N$-methyl-D-aspartate on cortical neurons, Science, 236 (1987) 589-593.

180 Pokorny, J. and Yamamoto, T., Postnatal ontogenesis of hippocampal CA1 area in rats. I. development of dendritic arborization in pyramidal neurons, Brain Res. Bull., 7 (1981) 113-120.

181 Pokorny, J. and Yamamoto, T., Postnatal ontogenesis of hippocampal CAI area in rats. II. Development of ultrastructure in stratum lacunosum and moleculare, Brain Res. Bull., 7 (1981) 121-130.

182 Potashner, S.J., The spontaneous and electrically evoked release from slices of guinea pig cerebral cortex of endogenous amino acids labeled via metabolism of $\mathrm{D}-\left[\mathrm{U}^{14} \mathrm{C}\right]$ glucose, $J$. Neurochem., 31 (1978) 177-186.

183 Purpura, D.P., Prelevic, S. and Santini, M., Postsynaptic potentials and spike variations in the feline hippocampus during postnatal ontogenesis, Exp. Neurol., 22 (1968) 408-422.

184 Price, M.T., Olney, J.W. and Cicero, T.J., Acute elevations of serum luteinizing hormone induced by kainic acid, $N$-methyl aspartic acid or homocysteic acid, Neuroendocrinology, 26 (1978) 352-358.

185 Raisman, G., Lawrence, J.M., Zhou, C.F. and Lindsey, R.M., Some neuronal, glial and vascular interactions which occur when developing hippocampal primordia are incorporated into adult host hippocampi. In A. Björklund and U. Stenevi (Eds.), Neural Grafting in the Mammalian CNS, Elsevier, Amsterdam, 1985 , pp. 125-150.

186 Ransom, R.W. and Stec, N.L., Cooperative modulation of [ $\left.{ }^{3} \mathrm{H}\right] \mathrm{MK}-801$ binding to the $N$-methyl-D-aspartate receptor-ion channel complex by L-glutamate, glycine and polyamines, $J$. Neurochem., 51 (1988) 830-836.

187 Rauschecker, J.P. and Hahn, S., Ketamine-xylazine anaesthesia blocks consolidation of ocular dominance changes in kitten visual cortex, Nature (Lond.), 326 (1987) 183-185.

188 Reh, T.A. and Constantine-Paton, M., Eye-specific segregation requires neural activity in 3-eyed Rana pipiens, J. Neurosci, 5 (1985) 1132-1143.

189 Reiter, H.O., Waitzman, D.M. and Stryker, M.P., Cortical activity blockade prevents ocular dominance plasticity in the kitten visual cortex, Exp. Brain Res., 65 (1986) 182-188.

190 Represa, A., Tremblay, E., Schoevart, D. and Ben-Ari, Y., Development of high-affinity kainate binding sites in human and rat hippocampi, Brain Research, 384 (1986) 170-174.

191 Represa, A., Tremblay, E. and Ben-Ari, Y., Transient increase of NMDA-binding sites in human hippocampus during development, Neurosci. Lett., 99 (1989) 61-66.

192 Robinson, M.B. and Coyle, J.T., Glutamate and related acidic excitatory neurotransmitters from basic science to clinical 
application, FASEB. J., 1 (1987) 446-455.

193 Rothman, S.M., Synaptic release of excitatory amino acid neurotransmitter mediates anoxic neuronal death, J. Neurosci., 4 (1984) 1884-1891.

194 Rothman, S.M., Thurston, J.H., Hauhart, R.E., Clark, G.D and Solomon, J.S., Ketamine protects hippocampal neurons from anoxia in vitro, Neuroscience, 21 (1987) 673-678.

195 Rothman, S.M. and Olney, J.W., Excitotoxicity and the NMDA receptor, Trends Neurosci., 10 (1987) 299-302.

196 Sanderson, C. and Murphy, S., Glutamate binding in the rat cerebral cortex during ontogeny, Dev. Brain Res., 2 (1982) 329-339.

197 Sandoval, M.E. and Cotman, C.W., Evaluation of glutamate as a neurotransmitter of cerebellar parallel fibers, Neurosci., 3 (1978) 199-206.

198 Schainker, B.A and Cicero, T.J., Acute central stimulation of luteinizing hormone by parenterally administered $\mathrm{N}$-methylD,L-aspartic acid in the male rat, Brain Research, 184 (1980) 425-437.

199 Schapiro, S. and Vukovich, K.R., Early experience effects upon cortical dendrites. A proposed model for development, Science, 167 (1970) 292-294.

200 Scheibel, M.E., Crandall, P.H. and Scheibel, A.B., The hippocampal-dentate complex in temporal lobe epilepsy; a golgi study, Epilepsia, 15 (1974) 55-80.

200a Scherer, W.S., Udin, S.B., The role of NMDA receptors in the development of binocular maps in Xenopus tectum, Soc. Neurosci. Abstr., 14 (1988) 272.16.

201 Schliebs, R., Kullmann, E. and Bigl, V., Development of glutamate binding sites in the visual structures of the rat brain. Effect of visual pattern deprivation, Biomed. Biochim. Acta, 4 (1986) 495-506.

202 Schmidt, W. and Wolf, G., High-affinity uptake of L$\left[{ }^{3} \mathrm{H}\right]$ glutamate and $\mathrm{D}-\left[{ }^{3} \mathrm{H}\right]$ aspartate during postnatal development of the hippocampal formation: a quantitative autoradiographic study, Exp. Brain Res., 70 (1988) 50-54.

203 Schwarcz, R., Brush, G.S., Foster, A.C. and French, E.D., Seizure activity and lesions after intrahippocampal quinolinic acid injection, Exp. Neurol, 84 (1984) 1-17.

204 Schwartzkroin, P.A., Development of rabbit hippocampus: physiology, Dev. Brain Res., 2 (1982) 448-462.

205 Sherwin, A.L. and Van Gelder, N.M., Amino acid and catecholamine markers of metabolic abnormalities in human focal epilepsy. In A.V. Delgado-Escueta, A.A. Ward Jr., D.M. Woodbury and R.J. Porter (Eds.), Advances in Neurology, Raven Press, New York, pp. 1011-1032.

206 Shimizu, K.A., Mizutani, A. and Inouye, M., Electron microscopic studies on the hypothalamic lesions in the mouse fetus caused by monosodium glutamate, Teratology, 8 (1973) 105.

207 Shinozaki, H., Pharmacology of the glutamate receptor, Prog. Neurobiol., 30 (1988) 399-435.

208 Silverstein, F.S., Buchanan, K. and Johnston, M.V., Perinatal hypoxia-ischemia disrupts striatal high-affinity $\left.{ }^{3} \mathrm{H}\right]$ glutamate uptake into synaptosomes, $J$. Neurochem., 47 (1986) 16141619.

209 Silverstein, F.S., Chen, R.C. and Johnston, M.V., The glutamate agonist quisqualic acid is neurotoxic in striatum and hippocampus of immature rat brain, Neurosci. Lett., 71 (1986) 13-18.

210 Silverstein, F.S., Torke, L., Barks, J. and Johnston, M.V., Hypoxia-ischemia produces focal disruption of glutamate receptors in developing brain, Dev. Brain Res., 34 (1987) 33-39.

211 Silverstein, F.S., McDonald, J.W. and Johnston, M.V., 3HTCP binding in hypoxic-ischemic brain, Soc. Neurosci. Abstr., 14 (1988) 169.3 .

212 Simon, R.P., Swan, J.H., Griffiths, T. and Meldrum, B.S., Blockade of $N$-methyl-D-aspartate receptors may protect against ischemic damage in the brain, Science, 226 (1984) 850-852.
213 Simon, R.P., Young, R.S., Stout, S. and Cheng, J., Inhibition of excitatory neurotransmission with kynurenate reduces brain injury in neonatal anoxia, Neurosci. Lett., 71 (1986) 361-364.

214 Sladeczek, F., Pin, J.P., Recasens, M., Bockaert, J. and Weiss, S., Glutamate stimulates inositol phosphate formation in striatal neurones, Nature (Lond.), 317 (1985) 717-719.

215 Sloviter, R.S., 'Epileptic' brain damage in rats induced by sustained electrical stimulation of the perforant path. I. Acute electrophysiological and light microscopic studies, Brain Res. Bull., 10 (1983) 675-697.

216 Smith, K.L., Turner, J. and Swann, J.W., Paired intracellular recordings reveal mono- and polysynaptic excitatory interactions in immature hippocampus, Soc. Neurosci. Abstr., 14 (1988) 351.16.

217 Snapir, N., Robinson, B. and Perek, M., Brain damage in male domestic fowl treated with monosodium glutamate, Poult. Sci., 50 (1971) 1511-1514.

218 Spencer, P.S., Ludolph, A., Dwived, M.P., Roy, D.N., Hugon, J. and Schaumburg, H.H., Lathyrism: evidence for role of the neuroexcitatory amino acid BOAA, Lancet, 2 (1986) 10661067.

219 Spencer, P.S., Nunn, P.B., Hugon, J., Ludolph, A., Ross, S.M., Roy, D.N. and Robertson, R.C., Guam amyotrophic lateral sclerosis-parkinsonism-dementia linked to a plant excitant neurotoxin, Science, 237 (1987) 517-522.

220 Steiner, H.X., McBean, G.J., Kohler, C., Roberts, P.J. and Schwarcz, R., Ibotenate-induced neuronal degeneration in immature rat brain, Brain Research, 307 (1984) 117-124.

221 Stelzer, A., Slater, N.T., Galvan, M. and ten Bruggencate, G., $N$-Methyl-D-aspartate receptors and hippocampal kindling. In T.P. Hicks, D. Lodge and M. McLennan (Eds.), Excitatory Amino Acids Transmission, Alan R. Liss, New York, 1987, pp. 71-74.

222 Stewart, G.R., Price, M., Olney, J., Harmant, B.K. and Cozzari, C., $N$-methyl-D-aspartate: an effective tool for lesioning basal forebrain cholinergic neurons of the rat, Brain Research, 369 (1986) 377-382.

223 Stone, T.W. and Connick, J.H., Quinolinic acid and other kynurenines in the central nervous system, Neurosci., 15 (1985) 597-617.

224 Stone, T.W. and Burton, N.R., NMDA receptors and ligands in the vertebrate CNS, Prog. Neurobiol., 30 (1988) 333-368.

225 Strauss, A.A., Modanlou, H.D. and Bosu, S.K., Neonatal manifestations of maternal phencyclidine (PCP) abuse, Pediatrics, 68 (4) (1981) 550-552.

226 Swann, J.W. and Brady, R.J., Penicillin-induced epileptogenesis in immature rat CA3 hippocampal pyramidal cells, Dev. Brain Res., 12 (1984) 243-254.

227 Tal, J., Price, M.T. and Olney, J.W., Neuroactive amino acids influence gonadotropin output by a suprapituitary mechanism in either rodents or primates, Brain Research, 273 (1983) 179-182.

228 Thomson, A.M., West, D.C. and Lodge, D., An $N$-methyl$D$-aspartate receptor mediated synapse in rat cerebral cortex: a site of action of ketamine?, Nature (Lond.), 313 (1985) 479-481.

229 Thomson, A.M., Walker, V.E. and Flynn, D.M., Glycine enhances NMDA-receptor mediated synaptic potentials in neocortical slices, Nature (Lond.), 338 (1989) 422-424.

230 Toth, L., Karcsu, S., Feledi, J. and Kreutzberg, G.W., Neurotoxicity of monosodium-L-glutamate in pregnant and fetal rats, Acta Neuropathol. (Berl.), 75 (1987) 16-22.

231 Tremblay, E., Roisin, M.P., Represa, A., Charriaut-Marlangue, C. and Ben-Ari, Y., Transient increased density of NMDA binding sites in developing rat hippocampus, Brain Research, 461 (1988) 393-396.

232 Tsumoto, T., Masui, H. and Sato, H., Excitatory amino acid transmitters in neuronal circuits of the cat visual cortex, $J$. Neurophysiol., 55 (1986) 469-483.

233 Tsumoto, T., Hagihara, K., Sato, H. and Hata, Y., NMDA 
receptors in the visual cortex of young kittens are more cffective than those of adult cats, Nature (Lond.), 327 (1987) 513-514.

234 Uckele, J.E., McDonald, J.W., Johnston, M.V. and Silverstein, F.S., Effect of glycine and glycine receptor antagonists on NMDA-induced brain injury, Neurosci. Lett., (1989) in press.

$234 a$ Udin, S.B., The role of visual experience in the formation of binocular projections in frogs, Cell. Mol. Neurobiol., 5 (1985) 85-102.

$234 \mathrm{~b}$ Udin, S.B., The development of the nucleus isthmi in Xenopus. II. Branching patterns of contralateral projecting isthmotectal axons during maturation of binocular maps, Vis. Neurosci., 2 (1989) 153-163.

235 Unnerstall, J.R. and Wamsley, J.K., Autoradiographic localization of high-affinity $\left[{ }^{3} \mathrm{H}\right] \mathrm{kainic}$ acid binding sites in the rat forebrain, Eur. J. Pharmacol., 86 (1983) 361-371.

236 Urbanski, H.K. and Ojeda, S.R., Activation of luteinizing hormone-releasing hormone release advances the onset of female puberty, Neuroendocrinology, 46 (1987) 273-276.

237 Vacanti, F.X. and Ames, A., Mild hypothermia and $\mathrm{Mg}^{++}$ protect against irreversible damage during CNS ischemia, Stroke, 15 (1984) 695-698.

238 Watkins, J.C. and Evans, R.H., Excitatory amino acid transmitters, Ann. Rev. Pharmacol. Toxicol., 21 (1981) 165-204.

239 Watkins, J.C. and Olverman, H.J., Agonist and antagonists for excitatory amino acid receptors, Trends Neurosci., 10 (1987) 265-272.

240 Welch, M.J. and Correa, G.A., PCP intoxication in young children and infants, Clin. Pediatr., 19 (1980) 510.

241 Westbrook, G.L. and Mayer, M.L., Micromolar concentrations of $\mathrm{Zn}^{2+}$ antagonize NMDA and GABA responses of hippocampal neurons, Nature (Lond.), 328 (1987) 640-643.

242 Wieloch, T., Lindval, O., Blomqvist, P. and Gage, F.H., Evidence for amelioration of ischemic neuronal damage in the hippocampal formation by lesion of the perforant path, Neurol. Res., 7 (1985) 24-26.

243 Wieloch, T., Hypoglycemia-induced neuronal damage prevented by an $N$-methyl-D-aspartate antagonist, Science, 230 (1985) 681-683.

244 Wolf, G. and Keilhoff, G., Kainate and glutamate neurotoxicity in dependence on the postnatal development with special reference to hippocampal neurons, Dev. Brain Res., 14 (1984) 15-21.

245 Young, A.B., Greenamyre, J.T., Hollingsworth, Z., Albin, R., D'Amato, C., Shoulson, I. and Penney, J.B., NMDA receptor losses in putamen from patients with Huntington's disease, Science, 241 (1988) 981-983.

246 Zimmer, J. and Gahwiler, B.H., Cellular and connective organization of slice cultures of the rat hippocampus and fascia dentata, J. Comp. Neurol., 228 (1984) 432-446. 